OPEN ACCESS

Edited by:

Abidemi James Akindele, University of Lagos, Nigeria

Reviewed by: Ahmed Elberry,

Beni-Suef University, Egypt

Basiru Olaitan Ajiboye,

Afe Babalola University, Nigeria

*Correspondence:

Adejuwon Adewale Adeneye adeneye2001@yahoo.com adejuwon.adeneye@ lasucom.edu.ng

Specialty section: This article was submitted to Translational Pharmacology, a section of the journal

Frontiers in Pharmacology

Received: 25 September 2020 Accepted: 23 November 2020

Published: 04 March 2021

Citation:

Olorundare $O E$, Adeneye $A A$, Akinsola $A O$, Ajayi AM, Agede $O A$, Soyemi SS, Mgbehoma Al, Okoye II,

Albrecht RM, Ntambi JM and

Crooks PA (2021) Therapeutic

Potentials of Selected Antihypertensive

Agents and Their Fixed-Dose Combinations Against Trastuzumab-

Mediated Cardiotoxicity.

Front. Pharmacol. 11:610331. doi: 10.3389/fphar.2020.610331

\section{Therapeutic Potentials of Selected Antihypertensive Agents and Their Fixed-Dose Combinations Against Trastuzumab-Mediated Cardiotoxicity}

\author{
Olufunke Esan Olorundare ${ }^{1}$, Adejuwon Adewale Adeneye ${ }^{2 *}$, Akinyele Olubiyi Akinsola ${ }^{1}$, \\ Abayomi Mayowa Ajayi ${ }^{3}$, Olalekan Ayodele Agede ${ }^{1}$, Sunday Sokunle Soyemi ${ }^{4}$, \\ Alban Ikenna Mgbehoma ${ }^{5}$, Ikechukwu Innocent Okoye ${ }^{6}$, Ralph M. Albrecht ${ }^{7}$, \\ James Mukasa Ntambi ${ }^{8}$ and Peter Anthony Crooks ${ }^{9}$
}

\begin{abstract}
${ }^{1}$ Department of Pharmacology and Therapeutics, Faculty of Basic Clinical Sciences, College of Health Sciences, University of Ilorin, Ilorin, Nigeria, ${ }^{2}$ Department of Pharmacology, Therapeutics and Toxicology, Faculty of Basic Clinical Sciences, Lagos State University College of Medicine, Ikeja, Nigeria, ${ }^{3}$ Department of Pharmacology and Therapeutics, Faculty of Basic Medical Sciences, University of Ibadan, Ibadan, Nigeria, ${ }^{4}$ Department of Pathology and Forensic Medicine, Faculty of Basic Clinical Sciences, Lagos State University College of Medicine, Ikeja, Nigeria, ${ }^{5}$ Department of Pathology and Forensic Medicine, Lagos State University Teaching Hospital, Ikeja, Nigeria, ${ }^{6}$ Department of Oral Pathology and Medicine, Faculty of Dentistry, Lagos State University College of Medicine, Ikeja, Nigeria, 'Department of Animal Sciences, University of Wisconsin, Madison, WI, United States, ${ }^{8}$ Department of Nutritional Sciences, College of Agricultural and Life Sciences, University of Wisconsin, Madison, Madison, WI, United States, ${ }^{9}$ Department of Pharmaceutical Sciences, College of Pharmacy, University of Arkansas for Medical Sciences, Little Rock, AR, United States
\end{abstract}

Trastuzumab (TZM) is useful in the clinical management of HER2-positive metastatic breast, gastric, and colorectal carcinoma but has been limited by its off-target cardiotoxicity. This study investigates the therapeutic potentials of $0.25 \mathrm{mg} / \mathrm{kg} / \mathrm{day}$ amlodipine, $0.035 \mathrm{mg} / \mathrm{kg} /$ day lisinopril, $5 \mathrm{mg} / \mathrm{kg} /$ day valsartan, and their fixed-dose combinations in TZM-intoxicated Wistar rats that were randomly allotted into 10 groups of 6 rats for each group. Group I rats were treated with $10 \mathrm{ml} / \mathrm{kg} /$ day sterile water orally and $1 \mathrm{ml} / \mathrm{kg} /$ day sterile water intraperitoneally; Groups II, III, and IV rats were orally gavaged with $5 \mathrm{mg} / \mathrm{kg} /$ day valsartan and $1 \mathrm{ml} / \mathrm{kg} /$ day sterile water intraperitoneally, $0.25 \mathrm{mg} / \mathrm{kg} /$ day amlodipine and $1 \mathrm{ml} / \mathrm{kg} /$ day sterile water via the intraperitoneal route, $0.035 \mathrm{mg} / \mathrm{kg} /$ day lisinopril and $1 \mathrm{ml} / \mathrm{kg} /$ day sterile water administered intraperitoneally, respectively. Group $\vee$ rats were orally treated with $10 \mathrm{ml} / \mathrm{kg} /$ day of sterile water prior to intraperitoneal administration of $2.25 \mathrm{mg} / \mathrm{kg} /$ day of $T Z M$. Groups VI-VIII rats were equally pretreated with $5 \mathrm{mg} / \mathrm{kg} /$ day valsartan, $0.25 \mathrm{mg} / \mathrm{kg} /$ day amlodipine, and $0.035 \mathrm{mg} / \mathrm{kg} /$ day lisinopril before intraperitoneal $2.25 \mathrm{mg} / \mathrm{kg} /$ day TZM treatment, respectively; Groups IX and $X$ rats were orally pretreated with the fixed-dose combinations of $0.25 \mathrm{mg} / \mathrm{kg} /$ day amlodipine $+0.035 \mathrm{mg} / \mathrm{kg} /$ day lisinopril and $5 \mathrm{mg} / \mathrm{kg} /$ day valsartan $+0.035 \mathrm{mg} / \mathrm{kg} /$ day lisinopril, respectively, before TZM treatment. Cardiac injury and tissue oxidative stress markers, complete lipids profile, histopathological, and immunohistochemical assays were the evaluating endpoints. Results showed that repeated TZM treatments caused profound increases in the serum TG and VLDL-c levels, serum cTnl and LDH levels, and cardiac tissue caspase-3 and -9 levels but decreased BCL-2 expression. TZM also profoundly attenuated CAT, SOD, GST and GPx activities, and increased MDA levels in the treated 
tissues. In addition, TZM cardiotoxicity was characterized by marked vascular and cardiomyocyte congestion and coronary artery microthrombi formation. However, the altered biochemical, histopathological, and immunohistochemical changes were reversed with amlodipine, lisinopril, valsartan, and fixed-dose combinations, although fixed-dose valsartan/lisinopril combination was further associated with hyperlipidemia and increased Al and CRI values and coronary artery cartilaginous metaplasia. Thus, the promising therapeutic potentials of amlodipine, lisinopril, valsartan and their fixed-dose combinations in the management of TZM cardiotoxicity, majorly mediated via antiapoptotic and oxidative stress inhibition mechanisms were unveiled through this study.

Keywords: Wistar rats, fixed-dose antihypertensive combinations, oxidative stress markers, cardiac injury biomarkers, trastuzumab cardiotoxicity

\section{INTRODUCTION}

Cancer remains a major public health issue all around the world and is presently considered the second leading cause of death globally, accounting for an estimated 9.6 million deaths or one in six deaths with approximately $70 \%$ of these deaths occurring in low- and middle-income countries in the year 2018 (World Health Organization, 2018; Siegel et al., 2020). This figure has been predicted to increase to 19 million sufferers by the year 2030 (Corremans et al., 2019). However, cancer treatment prognosis has tremendously improved in recent times due to better diagnostic tools, earlier detection, and more effective therapeutic strategies including novel-targeted therapies, one of which is the monoclonal antibody, trastuzumab.

Trastuzumab (TZM) (sold under the brand names Herceptin ${ }^{\circledR}$, Herzuma $^{\circledR}$, Ogivri ${ }^{\circledR}$, etc.) is a recombinant DNA-derived, humanized mouse IgG kappa monoclonal antibody targeted against the subdomain IV of the extracellular region of human epidermal growth factor receptor 2 (HER2)-expressed tumors (Poon et al., 2013; Porta et al., 2015; Fang et al., 2020).TZM is one of the HER2-targeted monoclonal antibodies approved for the clinical management of HER2 overexpressing metastatic solid tumors such as breast and gastric cancers (Lameire, 2014; Porta et al., 2015), gastroesophageal adenocarcinoma (Blackwell et al., 2010; Poon et al., 2013), and salivary duct carcinoma (Gibo et al., 2019). TZM binds to the extracellular membrane domain of HER 2 to inhibit proliferation, survival and reversal of the phenotype of HER2/neu expressing tumor cells (Mandaliya et al., 2015). The exact cytotoxic actions of TZM are believed to be multimodal and these include inhibition of: signal transduction pathways, extracellular domain cleavage, and DNA repair, as well as decreased angiogenesis, induction of cell cycle arrest, and activation of antibody dependent cellular cytotoxicity (Poon et al., 2013; Lameire, 2014). The wide clinical application of TZM has profoundly improved the survival and recovery chances of patients with advanced HER2-positive breast and gastric cancers but has reportedly been limited by its cumulative and reversible off-target organ toxicities, most common of which is cardiotoxicity (Hidalgo et al., 2013; Onitilo et al., 2014; Mohan et al., 2018).

There are reports of the potential role of some classes of antihypertensive agents as effective modulators of anthracycline- and trastuzumab-induced cardiotoxicities (Rygiel, 2016). These classes of antihypertensive drugs include angiotensin-converting enzyme inhibitors (ACEIs), angiotensin receptor blockers (ARBs), and beta $(\beta)_{1}$-adrenoreceptor blockers (Gujral et al., 2018; Sharma et al., 2018; Guglin et al., 2019; Ma et al., 2019; Guo et al., 2020) in the prevention of anthracycline- and TZM-induced cardiotoxicities (Wittayanukorn et al., 2018; Blanter and Frishman, 2019; Brown et al., 2020). In addition, ranolazine, a new anti-ischemia drug and a specific inhibitor of late sodium current, has been reported to attenuate TZM-induced heart dysfunction by reducing reactive oxygen species (ROS) production (Riccio et al., 2018). However, despite the availability and clinical trials of these potential antidotes, their effectiveness in ameliorating TZM-induced cardiotoxicity is still debatable. Therefore, this study is aimed at evaluating the possible therapeutic potential of amlodipine, lisinopril, and valsartan (being prototype of classical long-acting dihydropyridine calcium channel blockers, angiotensin-converting enzyme inhibitors, and angiotensin receptor blockers, respectively) and their fixed-dose [(amlodipine + lisinopril) and (valsartan + lisinopril)] combinations in acute TZM-induced cardiotoxicity in Wistar rats for the sole reason of therapeutic drug repurposing. In doing this, effects of the oral pretreatments with these drugs and their fixed-dose combinations on biochemical (cardiac enzyme markers, complete lipids profile, cardiac oxidative stress markers, and markers of apoptosis), histopathological, and immunohistochemical endpoints were evaluated in TZMinduced cardiotoxicity. The choice of the drug fixed-dose combinations was based on their reported high efficacies in regulating blood pressure and preventing complications in hypertensive patients (Naidu et al., 2000; Locatelli et al., 2002; Menne et al., 2008; Alhamdani, 2009; Bubnova et al., 2019).

\section{MATERIALS AND METHODS}

\section{Drugs and Chemicals}

Drugs used include trastuzumab injection with an accompanying sterile water vial (Biocon CANMab $440 \mathrm{mg}$ lyophilized powder ${ }^{\mathrm{TM}}$, Biocon Limited, Km 34 Tumkur Road, T-Bengur, Nelamangala Taluk, Bangalore-56 123, India), amlodipine besylate (Pfizer Norvasc 5 mg $^{\text {TM }}$, R-Pharm Germany GmbH, Heinrich-Mack-Str. 35, 89257 
Illertissen, Germany), lisinopril dihydrate (Zestril $5 \mathrm{mg}^{\mathrm{TM}}$, AstraZeneca United Kingdom Limited, Macclesfield, Cheshire, SK10 2NA, United Kingdom), and valsartan (Norvatis Diovan $160^{\mathrm{TM}}$, Norvatis Pharma AG, Basel, Switzerland). Chemicals such as hydrochloric acid ( $\mathrm{HCl}$ ), thiobarbituric acid (TBA), 1,2-dichloro4-nitrobenzene, trichloroacetic acid (TCA), sodium hydroxide, xylenol orange $(\mathrm{XO})$, potassium hydroxide, reduced glutathione (GSH), and hydrogen peroxide $\left(\mathrm{H}_{2} \mathrm{O}_{2}\right)$ were purchased from Sigma-Aldrich Chemical Co., St. Louis, MO, USA. All other chemicals were of analytical grade and were purchased from ThermoFisher Scientific, Cambridge, Massachusetts, USA. Other reagents and analytical test kits used include: Thermo Scientific Pierce $^{\mathrm{TM}} 36000$ Peroxidase IHC Detection Kits (Pierce Biotechnology, Rockford, IL 61105, USA), caspase 3 monoclonal antibody [(3CSP01 (7.1.44), catalog no. MA5-11516, ThermoFisher Scientific, Cambridge, Massachusetts, USA), BCL-2 monoclonal antibody (Catalog no. MA5-11757, ThermoFisher Scientific, Cambridge, Massachusetts, USA), avidin/streptavidin-horseradish peroxidase (HRP) conjugate (Product catalog: SA100-01, Invitrogen Life Technologies, Carlsbard, CA 92008, USA), DAB (3,3' diaminobenzidine) substrate working solution [Product catalog: 34001 (DAB), 34002 (DAB Substrate kit, Pierce Biotechnologies, Rockford, IL 61105, USA], dibutylphthalate polystyrene xylene (DPX) mountant (Sigma-Aldrich Inc., St. Louis, MO 63118, USA), lipid test kits (MAK043, MAK045, and TRO100) (SigmaAldrich Inc., St. Louis, MO 63118, USA), cardiac troponin-I ELISA kit (ab20001), and lactate dehydrogenase (LDH) assay kit (colorimetric) (ab102526) (Abcam Biotechnology Company, 1 Kendall Square, Suite B2304, Cambridge, MA 02139117, USA).

\section{Experimental Animals}

Sixty (60) male Wistar albino rats aged 8-12 weeks old and weighing 170-190 g used for the experiment were procured from the Animal House of the Lagos State University College of Medicine, Ikeja, Lagos State, Nigeria, after an ethical approval (UERC approval number: UERC/ASN/2020/2027) was obtained from the University of Ilorin Ethical Review Committee for Postgraduate Research. The rats were handled in accordance with international principles guiding the use and handling of experimental animals (National Research Council (US), 2011; Committee for the Update of the Guide for the Care and Use of Laboratory Animals). The experimental rats were placed on standard rat feed (Ladokun Feeds, Ibadan, Oyo State, Nigeria) and potable water ad libitum and maintained under standard laboratory conditions (ambient temperature: $23-26^{\circ} \mathrm{C}, 55 \pm 5 \%$ humidity, and 12/12-h alternating light and dark periodicity).

\section{Body Weight Measurement}

The body weights of rats were taken on days 1 and 7 of the experiment using a digital rodent weighing scale ( ${ }^{\circledR}$ Virgo Electronic Compact Scale, New Delhi, India). The obtained values were expressed in grams $(\mathrm{g})$.

\section{Experimental Induction of TZM-Induced Cardiotoxicity and Drug Treatments of Rats} Before the experiment started, rats were randomly allotted into 10 groups of 6 rats per group such that differences in-between and within groups of their weights were not more than $\pm 20 \%$ of the average weight of the sample population of rats used for the study. However, the choice of the therapeutic doses of amlodipine, lisinopril, valsartan and their fixed-dose combinations were made based on the results of the orientation studies earlier conducted by us. The dose of TZM adopted was as described by Poon et al., (2013) and Riccio et al., (2018).

In this experimental repeated dose model, Group I rats served as untreated control and were orally pretreated with $10 \mathrm{ml} / \mathrm{kg} /$ day of sterile water before i. p. treatment with $1 \mathrm{ml} / \mathrm{kg} /$ day of sterile water for 7 days (Table 1). Groups II, III, and IV rats were orally treated with $5 \mathrm{mg} / \mathrm{kg} /$ day of valsartan, $0.25 \mathrm{mg} / \mathrm{kg} /$ day of amlodipine, and $0.035 \mathrm{mg} / \mathrm{kg} /$ day of lisinopril, all dissolved in sterile water $3 \mathrm{~h}$ before $i$. $p$. treatment with $1 \mathrm{ml} / \mathrm{kg} /$ day of sterile water each day for 7 days, respectively. Group V rats were orally pretreated with $10 \mathrm{ml} / \mathrm{kg} /$ day of sterile water $3 \mathrm{~h}$ prior to i. p. $2.25 \mathrm{mg} / \mathrm{kg} / \mathrm{day}$ of TZM for 7 days (Table 1). Groups VI-VIII rats were equally pretreated with $5 \mathrm{mg} / \mathrm{kg} /$ day of valsartan, $0.25 \mathrm{mg} / \mathrm{kg} / \mathrm{day}$ of amlodipine, and $0.035 \mathrm{mg} / \mathrm{kg} /$ day of lisinopril, all dissolved in sterile water $3 \mathrm{~h}$ before $i$. $p$. treatment with $2.25 \mathrm{mg} / \mathrm{kg}$ of TZM for 7 days, respectively (Table 1). Groups IX and X rats were orally pretreated with the fixed-dose combinations of $0.25 \mathrm{mg} / \mathrm{kg} /$ day amlodipine $+0.035 \mathrm{mg} / \mathrm{kg} /$ day lisinopril in dissolved in sterile water and $5 \mathrm{mg} / \mathrm{kg} /$ day valsartan $+0.035 \mathrm{mg} / \mathrm{kg} /$ day lisinopril in dissolved in sterile water, respectively, $3 \mathrm{~h}$ before $i$. $p$. treatment with $2.25 \mathrm{mg} / \mathrm{kg}$ of $T Z M$ dissolved in sterile water for 7 days (Table 1 ).

\section{Blood Sample Collection}

$24 \mathrm{~h}$ following the last $T Z M$ dose, rats were sacrificed under inhaled light diethyl ether anesthesia. All the animals were subjected to an overnight fast before they were sacrificed. Blood samples were collected into plain blood sample bottles directly from the heart chambers with fine needle ( $21 \mathrm{G}$ size) mounted on a $5 \mathrm{ml}$ syringe (Hangzhou Longde Medical Products Co. Ltd., Hangzhou, China) without causing damage to the heart tissue.

\section{Harvesting and Weighing of Selected Vital Body Organs}

Selected vital organs such as the heart, liver, kidneys, and lungs of treated rats were identified, harvested en bloc, and weighed on a digital weighing scale.

\section{Measurement of Serum Cardiac Enzyme Markers and Lipids}

Blood samples obtained were collected into a $10 \mathrm{ml}$ plain sample bottle and allowed to clot and then centrifuged at 5,000 rpm for $5 \mathrm{~min}$ in order to separate out clear sera which were analyzed for the following biochemical parameters: serum cardiac injury markers [cardiac troponin I $(c T n I)$ and lactate dehydrogenase $(\mathrm{LDH})]$ and lipids (TG, TC, HDL-c, and LDL-c) using standard 
TABLE 1 | Drug treatment of rats.

\begin{tabular}{|c|c|}
\hline Groups & Treatments \\
\hline Group I & $10 \mathrm{ml} / \mathrm{kg} /$ day of sterile water given p.o. $+1 \mathrm{ml} / \mathrm{kg} /$ day of sterile water given i.p. for 7 days \\
\hline Group ॥ & $5 \mathrm{mg} / \mathrm{kg} /$ day of valsartan in sterile given p.o. $+1 \mathrm{ml} / \mathrm{kg} /$ day of sterile water given i.p. for 7 days \\
\hline Group III & $0.25 \mathrm{mg} / \mathrm{kg} /$ day of amlodipine in sterile water given p.o. $+1 \mathrm{ml} / \mathrm{kg}$ of sterile water given i.p. for 7 days \\
\hline Group IV & $0.035 \mathrm{mg} / \mathrm{kg} /$ day of lisinopril dissolved in sterile water given p.o. $+1 \mathrm{ml} / \mathrm{kg}$ of sterile water given i.p. for 7 days \\
\hline Group V & $10 \mathrm{ml} / \mathrm{kg} /$ day of sterile water given p.o. $+2.25 \mathrm{mg} / \mathrm{kg} /$ day of trastuzumab given i.p. for 7 days \\
\hline Group VI & $5 \mathrm{mg} / \mathrm{kg} /$ day of valsartan in sterile water given p.o. $+2.25 \mathrm{mg} / \mathrm{kg}$ of trastuzumab given i.p. for 7 days \\
\hline Group VII & $0.25 \mathrm{mg} / \mathrm{kg} /$ day of amlodipine in sterile water given p.o. $+2.25 \mathrm{mg} / \mathrm{kg} /$ day of trastuzumab given i.p. for 7 days \\
\hline Group VIII & $0.035 \mathrm{mg} / \mathrm{kg} /$ day of lisinopril dissolved in sterile water given p.o. $+2.25 \mathrm{mg} / \mathrm{kg} /$ day of trastuzumab given i.p. for 7 days \\
\hline Group IX & $\begin{array}{l}0.25 \mathrm{mg} / \mathrm{kg} / \text { day of amlodipine }+0.035 \mathrm{mg} / \mathrm{kg} / \text { day of lisinopril dissolved in sterile water and given p.o. for } 7 \text { days } \\
+2.25 \mathrm{mg} / \mathrm{kg} / \text { day of trastuzumab given i.p. for } 7 \text { days }\end{array}$ \\
\hline Group X & $\begin{array}{l}5 \mathrm{mg} / \mathrm{kg} / \text { day of valsartan }+0.035 \mathrm{mg} / \mathrm{kg} / \text { day of lisinopril dissolved in sterile water and given p.o. }+2.25 \mathrm{mg} / \mathrm{kg} / \mathrm{day} \text { of } \\
\text { trastuzumab given i.p. for } 7 \text { days }\end{array}$ \\
\hline
\end{tabular}

procedures described in the accompanying leaflets in the commercial test kits.

\section{Calculation of Atherogenic Index of Plasma (AIP) and Coronary Artery Index (CRI)}

AIP value was calculated as: $\left[\log _{10}(\mathrm{TG})(\mathrm{mg} / \mathrm{dl}) \div \mathrm{HDL}-\mathrm{c}(\mathrm{mg} / \mathrm{dl})\right.$ (Dobiasova and Frohlich, 2001; Dobiasova, 2004; Nansseu et al., 2016), while CRI was calculated as: TC (mg/dl) $\div \mathrm{HDL}-\mathrm{c}(\mathrm{mg} / \mathrm{dl})$ (Alladi and Shanmugasundaram, 1989).

\section{Determination of Antioxidant Activities in the Rat Cardiac Tissues}

Following the humane sacrifice of treated rats under light inhaled diethyl ether, rat heart was identified and gently dissected out en bloc and carefully divided into two halves (each consisting of the atrium and ventricle) using a new surgical blade. The left half of the heart was briskly rinsed in ice cold $1.15 \% \mathrm{KCl}$ solution in order to preserve the oxidative enzyme activities of the heart before being placed in a clean sample bottle which itself was in an ice pack-filled cooler. This was done to prevent the breakdown of the oxidative stress enzymes in these organs.

\section{Determination of Superoxide Dismutase (SOD) Activities in the Cardiac Tissues}

Enzyme activity of SOD was determined by its ability to inhibit the auto-oxidation of epinephrine by the increase in absorbance at $480 \mathrm{~nm}$ as described by Paoletti et al., (1986). SOD activity was subsequently calculated by measuring the change in absorbance at $480 \mathrm{~nm}$ for $5 \mathrm{~min}$.

\section{Determination of Catalase (CAT) Activity in the Cardiac Tissue}

Cardiac tissue CAT activity was determined using the method described by Hadwan (2018), and the specific activity of CAT was expressed as $\mathrm{U} / \mathrm{ml}$.

\section{Determination of Cardiac Tissue Reduced Glutathione (GSH), Glutathione Peroxidase (GPx), and Glutathione-S-Transferase (GST)}

\section{Activities}

GSH content in the cardiac tissues was estimated using the method earlier described by Rahman et al., (2006). To the cardiac homogenate, $10 \%$ TCA was added and centrifuged. $1 \mathrm{ml}$ of the supernatant was treated with $0.5 \mathrm{ml}$ of Elman's reagent $(19.8 \mathrm{mg}$ of 5,5-dithiobisnitro benzoic acid (DTNB) in $100 \mathrm{ml}$ of $0.1 \%$ sodium nitrate) and $3.0 \mathrm{ml}$ of phosphate buffer $(0.2 \mathrm{M}, \mathrm{pH} 8.0)$ and its absorbance was read at $412 \mathrm{~nm}$. Similarly, GPx and GST activities were determined using the method of Vontas et al., (2000).

\section{Determination of Cardiac Tissue Malondialdehyde (MDA) Contents}

$1 \mathrm{ml}$ of supernatant was added to $2 \mathrm{ml}$ of (1:1:1 ratio) TCA-TBA-HCl reagent (composition: thiobarbituric acid $0.37 \%$, $0.24 \mathrm{~N} \mathrm{HCl}$, and $15 \% \mathrm{TCA}$ ), boiled at $100^{\circ} \mathrm{C}$ for $15 \mathrm{~min}$, allowed to cool, and then centrifuged at 3,000 rpm for $10 \mathrm{~min}$ so as to remove the flocculent material. The supernatant was removed and its absorbance was read at $532 \mathrm{~nm}$ against a blank. MDA was calculated using the molar extinction for MDA-TBA complex of $1.56 \times 10^{5} \mathrm{~m}^{-1} \mathrm{~cm}^{-1}$ as described by Buege and Aust (1978).

\section{Histopathologic Assessment of the Heart Tissues}

Using the remaining equally divided harvested heart, the right halves of the six randomly selected rats from each treatment and control groups were subjected to histopathological examinations, the right ventricle being the most susceptible to TZM toxicity of the heart chambers (Calleja et al., 2015; Barthur et al., 2017; Jahangir et al., 2020). After rinsing in normal saline, the dissected right half of was preserved in $10 \%$ formosaline before it was completely dehydrated in absolute ethanol. It was then embedded in paraffin wax blocks. $4-5 \mu \mathrm{m}$ thick sections of the tissue were prepared from the paraffin block before staining with hematoxylin-eosin. Thereafter, these were examined under a photomicroscope (Model N-400ME, 
CEL-TECH Diagnostics, Hamburg, Germany) connected with a host computer. Sections were illuminated with white light from a $12 \mathrm{~V}$ halogen lamp $(100 \mathrm{~W})$ after filtering with a 520-nm monochromatic filter. The slides were examined for associated histopathological lesions (Slaoui and Fiette, 2011).

\section{Enzyme Linked Immunosorbent Assay (ELISA) for Determination of Cardiac Tissue Caspase-3 and Caspase-9}

Cardiac tissue levels of caspase- 3 and caspase- 9 were determined using the commercial Enzyme linked immunosorbent assay (ELISA) kits (Wuhan Elabscience Biotechnology Company Limited, No. 1 Shizishan Street, Hongshan District, Wuhan, Hubei, China) following the Manufacturers' instruction.

\section{Immunohistochemical Studies of Heart Tissues for Caspase-3 and BCL-2 Levels and Expressions \\ Assessment of Caspase-3 and BCL-2 Levels and Expressions}

This was done following the Manufacturer's procedures contained in the product leaflets accompanying the test kits. Small section of the right heart ventricle was trimmed off and was fixed in 10\% formalin neutral buffer for histological processing and paraffin embedding. 4-5- $\mu \mathrm{m}$ thin sections of the tissue were micro-sectioned, floated, and mounted on charged glass slides. The slides were labeled, arranged in racks, and placed in oven at $50-60^{\circ} \mathrm{C}$ for $20-30 \mathrm{~min}$ to melt excess paraffin. The slides containing heart tissues were further deparaffinized and prepared for heat-induced antigen retrieval in citrate buffer solution ( $10 \mathrm{mM}$ citric acid, $\mathrm{pH}$ 6.0). The staining was performed using Thermo Scientific Pierce ${ }^{\mathrm{TM}} 36000$ Peroxidase IHC Detection Kits with slight modification of the procedure. Endogenous peroxidase activity was quenched by incubating heart tissues for $30 \mathrm{~min}$ in Peroxidase Suppressor and washed three times in wash buffer. Blocking buffer was added to the slides and incubated for $30 \mathrm{~min}$. Excess buffer was blotted from the tissue sections, before addition of primary antibodies: Caspase- 3 monoclonal antibody, BCL-2 monoclonal antibody at a dilution of 1 : 100 , and left overnight in a humidified chamber at $4^{\circ} \mathrm{C}$. Afterward, slides were washed two times for 3 min with wash buffer. The tissue sections were treated with biotinylated secondary antibody and incubated for $30 \mathrm{~min}$. The slides were washed thrice for $3 \mathrm{~min}$ each with wash buffer, treated and incubated with avidin/ streptavidin-horseradish peroxidase conjugate for another $30 \mathrm{~min}$, and washed three times for 3 min each with wash buffer. The tissues were incubated with metal-enhanced $\mathrm{DAB}$ (3,3' diaminobenzidine) substrate working solution for $5 \mathrm{~min}$ for desired staining to achieve. The slides were rinsed with distilled water and drained. Adequate amount of Mayer's hematoxylin stain was dropped on the slide to cover the entire tissue surface and incubated for 1-2 min at room temperature. Hematoxylin stain was then drained off and the slides washed several times with distilled water. The slides prepared were mounted with cover slips and dibutylphthalate polystyrene xylene (DPX) mountant for histology.

\section{Scoring-Based Stain Intensity}

Photomicrographs were taken with AmScope MU900 9MP USB2.0 Microscope Digital Camera attached to Fisher Science Education $^{\mathrm{TM}}$ 160-Series University/Laboratory Compound Microscope (Model: S2387, Fisher Scientific, California, United States). The images were quantified for staining intensity using Fiji (open source image processing package based on ImageJ) software (Varghese et al., 2014).

\section{Statistical Analysis}

Data were presented as mean \pm SD and mean \pm SEM of six observations for the body weight/percentage body weight changes and biochemical parameters, respectively, while data for immunohistochemical analysis were expressed as mean \pm SEM of four observations in duplicates. One-way ANOVA followed by Turkey's post hoc test, on GraphPad Prism version 5, was used for statistical analysis of the data obtained. Statistical significance was considered at $p<0.05, p<0.001$, and $p<0.0001$.

\section{RESULTS}

\section{Effect of Amlodipine, Lisinopril, Valsartan and Their Fixed-Dose Treatments on Body Weight Changes ( $\% \Delta$ bwt.)}

Effects of repeated daily intraperitoneal injection with $2.25 \mathrm{mg} / \mathrm{kg}$ of $T Z M$ and oral pretreatments with ADP, LSP, VAL and the fixed-dose combinations of ADP + LSP and VAL + LSP, respectively, on the average body weight and \% $\Delta$ bwt. of rats on days 1 and 7 are as indicated in Table 2. Oral pretreatments with ADP and LSP to normal rats resulted in significant $(p<0.001)$ reductions in $\% \Delta$ bwt. when compared to Group I values. Similarly, i. p. TZM treatment and oral pretreatments with ADP, LSP, VAL and their combinations caused similar significant $(p<0.001)$ weight loss in TZMintoxicated rats when compared to Group I rats (Table 2).

\section{Effect of Amlodipine, Lisinopril, Valsartan and their Fixed-Dose Combinations on the Relative Organ Weights of TZM-Treated Rats} TZM treatment did not cause any significant $(p>0.05)$ alterations in RHW, RLW, and RKW relative to Group I values (Table 3). Similar effect was recorded for TZM-intoxicated rats pretreated with ADP, LSP, VAL and their fixed-dose combinations (Table 3).

\section{Effect of Amlodipine, Lisinopril, Valsartan and Their Fixed-Dose Combinations on the Serum Lipids (TG, TC, HDL-C, LDL-C, and VLDL-C) Levels in TZM-Treated Rats}

Repeated intraperitoneal TZM injections resulted in a significant $(p<$ 0.05 ) increase in the serum TG levels when compared to untreated normal control values, while ADP, LSP, VAL and their fixed-dose combination pretreatments resulted in significant $(p<0.05)$ reduction in serum TG levels when compared to untreated TZM-intoxicated rats 
TABLE 2 | Effect of repeated oral treatment with amlodipine, lisinopril, valsartan and their fixed-dose combinations on the average body weight and percentage body weight changes (\% $\triangle$ bwt.) of $T Z M$-treated rats.

\begin{tabular}{|c|c|c|c|}
\hline Groups & Body wt. on Day 1 (g) & Body wt. on Day 7 (g) & $\% \Delta$ bwt. \\
\hline I & $208.60 \pm 32.22$ & $223.20 \pm 35.12$ & $06.95 \pm 05.03$ \\
\hline ॥ & $203.00 \pm 17.43$ & $216.70 \pm 18.64$ & $06.79 \pm 03.83$ \\
\hline III & $200.60 \pm 28.18$ & $207.10 \pm 30.61$ & $03.25 \pm 02.76^{b}$ \\
\hline IV & $206.10 \pm 20.88$ & $208.80 \pm 18.82$ & $02.12 \pm 01.91^{\mathrm{b}-}$ \\
\hline V & $194.90 \pm 11.56$ & $195.30 \pm 16.28$ & $00.47 \pm 10.60^{\mathrm{b}-}$ \\
\hline $\mathrm{VI}$ & $201.40 \pm 16.36$ & $204.40 \pm 16.00$ & $01.57 \pm 03.85^{b-}$ \\
\hline VII & $202.80 \pm 15.36$ & $209.30 \pm 19.05$ & $03.13 \pm 02.99^{b-}$ \\
\hline VIII & $204.60 \pm 13.59$ & $210.80 \pm 06.87$ & $02.98 \pm 03.70^{\mathrm{b}-}$ \\
\hline IX & $207.00 \pm 10.24$ & $201.80 \pm 13.34$ & $01.80 \pm 03.17^{b-}$ \\
\hline$x$ & $194.80 \pm 20.82$ & $198.90 \pm 24.05$ & $02.08 \pm 03.63^{b-}$ \\
\hline \multicolumn{4}{|c|}{$\begin{array}{l}\text { b- represents a significant decrease at } p<0.001 \text { when compared to untreated normal } \\
\text { control (Group I) and valsartan-treated rats (Group II). } \\
\text { Groups I: untreated normal control; Group II: } 5 \mathrm{mg} / \mathrm{kg} / \text { day valsartan; Group III: } \\
0.25 \mathrm{mg} / \mathrm{kg} / \text { day amlodipine; Group IV: } 0.035 \mathrm{mg} / \mathrm{kg} / \text { day lisinopril; Group V: untreated } \\
\text { TZM control; Groups VI: } 5 \mathrm{mg} / \mathrm{kg} / \text { day valsartan }+2.25 \mathrm{mg} / \mathrm{kg} / \text { day TZM; Group VII: } \\
0.25 \mathrm{mg} / \mathrm{kg} / \text { day amlodipine +2.25 mg/kg/day TZM; Group VIII: } 0.035 \mathrm{mg} / \mathrm{kg} / \text { day } \\
\text { lisinopril +2.25 mg/ } / \mathrm{kg} / \text { day TZM; Groups IX: } 0.25 \mathrm{mg} / \mathrm{kg} / \text { day amlodipine }+0.035 \mathrm{mg} / \mathrm{kg} / \\
\text { day lisinopril] + } 2.25 \mathrm{mg} / \mathrm{kg} / \text { day TZM; Group X: [5 mg/ } / \mathrm{kg} / \text { day valsartan }+0.035 \mathrm{mg} / \mathrm{kg} / \\
\text { day lisinopril] + } 2.25 \mathrm{mg} / \mathrm{kg} / \text { day TZM. }\end{array}$} \\
\hline
\end{tabular}

(Table 4). Although TZM i. p. treatment did not significantly $(p>0.05)$ alter the serum TC levels, but oral pretreatment with VAL significantly $(p<0.05)$ reduced serum TC levels while ADP $+\mathrm{LSP}$ and VAL $+\mathrm{LSP}$ significantly $(p<0.05)$ elevated serum TC levels in TZM-intoxicated rats (Table 4). Similarly, oral pretreatments with the fixed-dose ADP + LSP and VAL + LSP combinations induced significant $(p<0.05)$ increases in the serum LDL-c and VLDL-c levels in TZM-intoxicated rats.

\section{Amlodipine, Lisinopril, Valsartan and Their Fixed-Dose Combinations on the Atherogenic Index and Coronary Artery Disease Index of TZM-Treated Rats}

Repeated intraperitoneal $2.25 \mathrm{mg} / \mathrm{kg} /$ day $T Z M$ injection for 7 days to treated rats resulted in a significant $(p<0.05)$ increase in AI without any significant $(p>0.05)$ alterations in the CRI values when compared to the untreated control (Group I) (Table 5). However, with ADP, LSP, and VAL pretreatments, there were significant $(p<0.05$ and $p<0.001)$ decreases in the AI values but no significant $(p>0.05)$ alterations in CRI values when compared to the untreated TZM control (Group V) values (Table 5). Conversely, fixed-dose [(ADP + LSP) and (VAL + LSP)] combination pretreatments significantly $(p<0.05, p<0.001$, and $p<$ 0.0001 ) increased the AI and CRI values with the higher values induced by the VAL + LSP combinations than untreated TZM-intoxicated (Group V) values (Table 5).

\section{Amlodipine, Lisinopril, Valsartan and Their Fixed-Dose Combinations on Cardiac Marker Enzymes (cTnl and LDH) of TZM-Treated Rats}

Repeated ADP, LSP, and VAL pretreatments did not significantly $(p>$ $0.05)$ cause alterations in the serum $c \operatorname{TnI}$ and LDH. However, repeated intraperitoneal TZM injections resulted in significant increases $(p<$
TABLE 3 | Effect of repeated oral treatment with amlodipine, lisinopril, valsartan and their fixed-dose combinations on the relative organ weight of TZMtreated rats.

\begin{tabular}{lcccc} 
Group & \multicolumn{4}{c}{ Relative organ weight } \\
\cline { 2 - 5 } & Heart & Liver & Kidney & Lungs \\
\hline I & $0.33 \pm 0.05$ & $3.34 \pm 0.56$ & $0.55 \pm 0.06$ & $0.80 \pm 0.09$ \\
II & $0.34 \pm 0.06$ & $3.45 \pm 0.77$ & $0.56 \pm 0.12$ & $0.84 \pm 0.20$ \\
III & $0.31 \pm 0.05$ & $3.24 \pm 0.35$ & $0.62 \pm 0.07$ & $0.78 \pm 0.19$ \\
IV & $0.31 \pm 0.06$ & $3.20 \pm 0.40$ & $0.60 \pm 0.05$ & $0.77 \pm 0.18$ \\
V & $0.36 \pm 0.06$ & $3.24 \pm 0.60$ & $0.59 \pm 0.09$ & $0.83 \pm 0.14$ \\
VI & $0.28 \pm 0.03$ & $3.17 \pm 0.34$ & $0.63 \pm 0.07$ & $0.70 \pm 0.08$ \\
VII & $0.34 \pm 0.03$ & $3.30 \pm 0.49$ & $0.61 \pm 0.10$ & $0.74 \pm 0.10$ \\
VIII & $0.30 \pm 0.03$ & $3.28 \pm 0.24$ & $0.56 \pm 0.06$ & $0.70 \pm 0.17$ \\
IX & $0.35 \pm 0.02$ & $3.44 \pm 0.38$ & $0.58 \pm 0.55$ & $0.69 \pm 0.08$ \\
X & $0.35 \pm 0.05$ & $3.53 \pm 0.62$ & $0.59 \pm 0.04$ & $0.73 \pm 0.15$
\end{tabular}

Groups I: untreated normal control; Group II: $5 \mathrm{mg} / \mathrm{kg} /$ day valsartan; Group III: $0.25 \mathrm{mg} / \mathrm{kg} /$ day amlodipine; Group IV: $0.035 \mathrm{mg} / \mathrm{kg} /$ day lisinopril; Group V: untreated TZM control; Groups VI: 5 mg/kg/day valsartan +2.25 mg/kg/day TZM; Group VII: $0.25 \mathrm{mg} / \mathrm{kg} /$ day amlodipine $+2.25 \mathrm{mg} / \mathrm{kg} /$ day TZM; Group VIII: $0.035 \mathrm{mg} / \mathrm{kg} / \mathrm{day}$ lisinopril +2.25 mg/kg/day TZM; Groups IX: $[0.25 \mathrm{mg} / \mathrm{kg} /$ day amlodipine +0.035 mg/kg/ day lisinopril] + 2.25 mg/kg/day TZM; Group X: [5 mg/kg/day valsartan +0.035 mg/kg/ day lisinopril] + $2.25 \mathrm{mg} / \mathrm{kg} /$ day $T Z M$.

0.0001) in the serum $c T n I$ and $\mathrm{LDH}$ levels when compared to that of untreated negative (control) (Group I) values (Table 6). With oral pretreatments with ADP, LSP, VAL and their fixed-dose combinations $[(\mathrm{ADP}+\mathrm{LSP})$ and $(\mathrm{VAL}+\mathrm{LSP})]$, increases in the serum $c$ TnI and LDL levels were significantly $(p<0.05, p<0.001$ and $p<0.0001)$ attenuated in TZM-intoxicated rats, with the most significant attenuation recorded in rats orally pretreated with the fixed-dose ADP + LSP combination (Table 6). Similar effects were recorded in normal rats orally treated with VAL, ADP, and LSP (Table 6).

\section{Amlodipine, Lisinopril, Valsartan and Their Fixed-Dose combinations on the Cardiac Tissue Oxidative Stress Markers (GSH, GST, GPX, SOD, CAT, and MDA) of TZM-Treated Rats}

TZM intraperitoneal injection to treated rats resulted in significant attenuation $(p<0.001$ and $p<0.0001)$ in SOD, CAT, GST and GPx activities, and GSH levels, while there were significant increases $(p<$ 0.001 ) in the MDA activities in the treated cardiac tissue (Table 7). However, repeated oral treatments with ADP, LSP, VAL and their fixed-dose combinations $[(\mathrm{ADP}+\mathrm{LSP})$ and (VAL + LSP) $]$ significantly $(p<0.05, p<0.001, p<0.0001)$ attenuated the alterations in the activities of these enzyme markers in the cardiac tissue restoring their activities to normal as recorded for Groups I-IV values (Table 7 ).

\section{Histopathologic Assessment of Drug-Treated Cardiac Tissues}

Repeated intraperitoneal injections of rats with $2.25 \mathrm{mg} / \mathrm{kg} /$ day of TZM for 7 days resulted in marked vascular and cardiomyocyte congestion, intraparenchymal hemorrhage, and coronary artery microthrombi formation (Figure 5) when compared to normal 
TABLE 4 | Effect of repeated oral administration of amlodipine, lisinopril, valsartan and their fixed-dose combinations on serum lipid profile of TZM-treated rats.

\begin{tabular}{|c|c|c|c|c|c|}
\hline \multirow[t]{2}{*}{ Groups } & \multicolumn{5}{|c|}{ Serum lipids } \\
\hline & $\mathrm{TG}(\mathrm{mmol} / \mathrm{l})$ & TC (mmol/l) & HDL-c (mmol/l) & LDL-c (mmol/l) & VLDC-c (mmol/l) \\
\hline I & $0.71 \pm 0.11$ & $1.10 \pm 0.21$ & $0.45 \pm 0.06$ & $0.40 \pm 0.11$ & $0.32 \pm 0.05$ \\
\hline$\|$ & $1.00 \pm 0.15$ & $1.66 \pm 0.20^{a+}$ & $0.48 \pm 0.08$ & $0.73 \pm 0.07$ & $0.45 \pm 0.07$ \\
\hline III & $0.86 \pm 0.08$ & $1.32 \pm 0.08$ & $0.39 \pm 0.01$ & $0.53 \pm 0.09$ & $0.39 \pm 0.04$ \\
\hline IV & $1.02 \pm 0.17$ & $1.47 \pm 0.12$ & $0.42 \pm 0.04$ & $0.59 \pm 0.10$ & $0.46 \pm 0.08$ \\
\hline V & $1.17 \pm 0.21^{a+}$ & $1.20 \pm 0.26$ & $0.43 \pm 0.06$ & $0.49 \pm 0.06$ & $0.52 \pm 0.08^{a+}$ \\
\hline VI & $0.70 \pm 0.05^{a^{*}}$ & $1.05 \pm 0.15^{\mathrm{a}^{\star}}$ & $0.37 \pm 0.04$ & $0.52 \pm 0.13$ & $0.32 \pm 0.02$ \\
\hline VII & $0.95 \pm 0.25$ & $1.22 \pm 0.14$ & $0.32 \pm 0.02$ & $0.47 \pm 0.06$ & $0.51 \pm 0.10^{a+}$ \\
\hline VIII & $0.85 \pm 0.20^{\mathrm{a}^{*}}$ & $1.15 \pm 0.16$ & $0.33 \pm 0.04$ & $0.43 \pm 0.06$ & $0.38 \pm 0.09$ \\
\hline IX & $0.90 \pm 0.14^{\mathrm{a}^{*}}$ & $1.72 \pm 0.13^{\mathrm{a}+\mathrm{a}}$ & $0.40 \pm 0.03$ & $0.92 \pm 0.15^{b+, b}$ & $0.41 \pm 0.06$ \\
\hline$x$ & $0.48 \pm 0.03^{\mathrm{c}^{*}}$ & $1.67 \pm 0.09^{a+, a}$ & $0.36 \pm 0.02$ & $1.10 \pm 0.09^{c+, c}$ & $0.22 \pm 0.01^{a^{*}}$ \\
\hline
\end{tabular}

cardiac histoarchitecture in untreated normal rat heart (Figure 1A). Individual oral pretreatments with VAL and ADP to normal rats did not cause any remarkable histological changes in the cardiac histoarchitecture (Figures 1B and D) although LSP induced severe myocardial congestion and diffuse myocardial lymphocytic infiltration (Figure 1C). However, in TZM-intoxicated rats orally pretreated with VAL, there was coronary artery recanalization (Figure 1F), while there were mild congestion with sparse ymphocytic infiltration (Figure 1G) and coronary arterial wall cartilaginous metaplasia (Figure $\mathbf{1 H}$ ) in ADP and LSP-pretreated cardiac tissues, respectively. Fixed-dose [(ADP + LSP) and (VAL + LSP)] combination pretreatments were associated with mild

TABLE 5 | Effect of amlodipine, lisinopril, valsartan and their fixed-dose combinations on atherogenic index of plasma (AIP) and coronary artery disease index (CRI) in TZM-intoxicated rats.

\begin{tabular}{lcc}
\hline Treatment Groups & AIP & CRI \\
\hline I & $-0.01 \pm 0.05$ & $02.95 \pm 0.14$ \\
II & $0.06 \pm 0.17^{\mathrm{a}-}$ & $03.45 \pm 0.11$ \\
III & $0.09 \pm 0.08^{\mathrm{a}-}$ & $03.35 \pm 0.13$ \\
IV & $0.01 \pm 0.17^{\mathrm{a}-}$ & $03.53 \pm 0.19$ \\
V & $0.11 \pm 0.03^{\mathrm{a}^{+}}$ & $03.43 \pm 0.15$ \\
VI & $-0.09 \pm 0.09^{\mathrm{c}-}$ & $02.83 \pm 0.10$ \\
VII & $0.09 \pm 0.06^{\mathrm{a}-}$ & $03.86 \pm 0.56$ \\
VIII & $-0.44 \pm 0.13^{\mathrm{c}-}$ & $03.42 \pm 0.13$ \\
IX & $0.22 \pm 0.15^{\mathrm{b}+}$ & $04.40 \pm 0.40^{\mathrm{a}+}$ \\
$X$ & $03.19 \pm 0.40^{\mathrm{c}+}$ & $04.82 \pm 0.52^{\mathrm{a}+}$
\end{tabular}

$a^{*}$ represents a significant increase at $p<0.05$ when compared to untreated control (Group I); ${ }^{b+}$ and ${ }^{c+}$ represent significant increases at $p<0.001$ and $p<0.0001$, respectively, while ${ }^{a-}$ and $^{c-}$ represent significant decreases at $\mathrm{p}<0.05$ and $\mathrm{p}<0.0001$, respectively, when compared to untreated TZM-intoxicated (Group V) values. Groups I: untreated normal control; Group II: $5 \mathrm{mg} / \mathrm{kg} /$ day valsartan; Group III: $0.25 \mathrm{mg} / \mathrm{kg} /$ day amlodipine; Group IV: $0.035 \mathrm{mg} / \mathrm{kg} /$ day lisinopril; Group V: untreated TZM control; Groups VI: $5 \mathrm{mg} / \mathrm{kg} /$ day valsartan $+2.25 \mathrm{mg} / \mathrm{kg} /$ day TZM; Group VIl: $0.25 \mathrm{mg} / \mathrm{kg} /$ day amlodipine $+2.25 \mathrm{mg} / \mathrm{kg} /$ day TZM; Group VIIl: $0.035 \mathrm{mg} / \mathrm{kg} /$ day lisinopril +2.25 mg/kg/day TZM; Groups IX: $[0.25 \mathrm{mg} / \mathrm{kg} /$ day amlodipine $+0.035 \mathrm{mg} / \mathrm{kg} /$ day lisinopril] + $2.25 \mathrm{mg} / \mathrm{kg} /$ day TZM; Group X: [5 mg/kg/day valsartan $+0.035 \mathrm{mg} / \mathrm{kg} /$ day lisinopril] + $2.25 \mathrm{mg} / \mathrm{kg} /$ day $T Z M$. myocardial congestion (Figure 1I) and coronary arterial wall cartilaginous metaplasia (Figure 1J), respectively.

\section{Amlodipine, Lisinopril, Valsartan and Their Fixed-Dose Combinations on TZM-Treated Cardiac Tissue Caspase-3 and Caspase-9 Levels}

Evaluation of the cardiac tissue apoptotic marker level, caspase-3, using ELISA technique showed that caspase- 3 was significantly $(p<0.05)$ elevated in untreated TZM-treated (Group V) cardiac tissues when compared with the untreated normal control
TABLE 6 | Effect of amlodipine, lisinopril, valsartan and their fixed-dose combinations [(ADP + LSP) and (VAL + LSP)] on serum cTnl and LDH in TZMintoxicated rats.

\begin{tabular}{|c|c|c|}
\hline Treatment groups & $c T n l(n g / m l)$ & LDH (U/L) \\
\hline I & $1.04 \pm 0.18$ & $7,521.00 \pm 770.40$ \\
\hline$\|$ & $0.87 \pm 0.19^{c-}$ & $5,620.00 \pm 448.70^{c-}$ \\
\hline III & $1.17 \pm 0.24^{\mathrm{c}-}$ & $5,553.00 \pm 664.20^{c-}$ \\
\hline IV & $2.27 \pm 0.93^{\mathrm{c}-}$ & $6,187.00 \pm 1,046.00^{c-}$ \\
\hline V & $17.09 \pm 1.45^{\mathrm{c}+}$ & $16769.00 \pm 2,350.00^{c+}$ \\
\hline $\mathrm{VI}$ & $3.93 \pm 1.29^{\mathrm{b}-}$ & $6,771.00 \pm 1,586.00^{\mathrm{c}-}$ \\
\hline VII & $7.52 \pm 2.25^{a-}$ & $4,685.00 \pm 381.30^{c-}$ \\
\hline VIII & $4.43 \pm 1.79^{b-}$ & $5,196.00 \pm 554.00^{c-}$ \\
\hline IX & $0.87 \pm 0.35^{\mathrm{c}-}$ & $3,694.00 \pm 384.30^{c-}$ \\
\hline$x$ & $2.95 \pm 1.01^{\mathrm{c}-}$ & $5,787.00 \pm 779.60^{\mathrm{C}-}$ \\
\hline
\end{tabular}

${ }^{c+}$ represents a significant increase at $p<0.0001$ when compared to untreated negative control (Group I) values, while ${ }^{a-,} b_{-}$, and ${ }^{c-}$ represent significant decreases at $p<0.05$, $p<0.001$, and $p<0.0001$, respectively, when compared to untreated TZM-intoxicated (Group V) control values, respectively.

Groups I: untreated normal control; Group II: $5 \mathrm{mg} / \mathrm{kg} /$ day valsartan; Group III: $0.25 \mathrm{mg} / \mathrm{kg} /$ day am/odipine; Group IV: $0.035 \mathrm{mg} / \mathrm{kg} /$ day lisinopril; Group V: untreated TZM control; Groups VI: $5 \mathrm{mg} / \mathrm{kg} /$ day valsartan $+2.25 \mathrm{mg} / \mathrm{kg} /$ day TZM; Group VIl: $0.25 \mathrm{mg} / \mathrm{kg} /$ day am/odipine $+2.25 \mathrm{mg} / \mathrm{kg} /$ day TZM; Group VIIl: $0.035 \mathrm{mg} / \mathrm{kg} /$ day lisinopril $+2.25 \mathrm{mg} / \mathrm{kg} /$ day TZM; Groups IX: [0.25 mg/kg/day am/odipine +0.035 mg/kg/ day lisinopril] + $2.25 \mathrm{mg} / \mathrm{kg} /$ day TZM; Group X: [5 mg/kg/day valsartan $+0.035 \mathrm{mg} / \mathrm{kg} /$ day lisinopril] + $2.25 \mathrm{mg} / \mathrm{kg} /$ day $T Z M$. 
TABLE 7 | Antioxidant activities of amlodipine, lisinopril, valsartan and their fixed-dose combinations in TZM-intoxicated cardiac tissue.

\begin{tabular}{|c|c|c|c|c|c|c|}
\hline \multirow[t]{2}{*}{ Groups } & \multicolumn{6}{|c|}{ Antioxidant parameters } \\
\hline & GSH & GST & GPx & SOD & CAT & MDA \\
\hline I & $83.13 \pm 5.77$ & $30.80 \pm 0.48$ & $93.63 \pm 6.18$ & $4.09 \pm 0.11$ & $23.02 \pm 0.71$ & $1.85 \pm 0.31$ \\
\hline$\|$ & $69.83 \pm 2.43^{a+}$ & $31.67 \pm 0.45^{b+}$ & $82.07 \pm 4.30^{\mathrm{b}+}$ & $4.44 \pm 0.31^{\mathrm{c}+}$ & $25.28 \pm 1.55^{\mathrm{b}+}$ & $1.87 \pm 0.30^{\mathrm{c}^{\star *}}$ \\
\hline III & $76.07 \pm 2.62^{b+}$ & $36.06 \pm 0.43^{b+}$ & $89.93 \pm 3.81^{b+}$ & $4.41 \pm 0.31^{\mathrm{c}+}$ & $26.11 \pm 1.09^{b+}$ & $1.98 \pm 0.28^{\mathrm{C}^{\star \star}}$ \\
\hline IV & $92.00 \pm 3.77^{\mathrm{c}+}$ & $40.31 \pm 1.81^{\mathrm{b}+}$ & $102.30 \pm 6.99^{c+}$ & $4.72 \pm 0.30^{\mathrm{c}+}$ & $26.12 \pm 1.40^{\mathrm{b}+}$ & $1.55 \pm 0.24^{\mathrm{C}^{\star \star}}$ \\
\hline V & $47.97 \pm 1.43^{\mathrm{C}^{-}}$ & $21.90 \pm 2.51^{c-}$ & $53.87 \pm 2.71^{\mathrm{c}-}$ & $2.01 \pm 0.25^{\mathrm{c}-}$ & $14.07 \pm 1.48^{\mathrm{b}-}$ & $4.16 \pm 0.44^{\mathrm{C}^{\star}}$ \\
\hline VI & $106.60 \pm 15.76^{\mathrm{c+}}$ & $36.38 \pm 0.53^{b+}$ & $97.73 \pm 2.51^{\mathrm{c+}}$ & $4.07 \pm 0.15^{\mathrm{c}+}$ & $24.61 \pm 1.00^{\mathrm{b}+}$ & $1.78 \pm 0.48^{\mathrm{c}^{\star \star}}$ \\
\hline VII & $76.50 \pm 2.84^{\mathrm{b}+}$ & $34.78 \pm 0.43^{b+}$ & $99.0 \pm 1.54^{\mathrm{C}+}$ & $4.03 \pm 0.15^{\mathrm{c}+}$ & $28.66 \pm 1.58^{\mathrm{b}+}$ & $1.64 \pm 0.81^{\mathrm{c}^{\star \star}}$ \\
\hline VIII & $89.24 \pm 7.32^{\mathrm{C+}}$ & $35.31 \pm 1.63^{b+}$ & $100.60 \pm 6.91^{\mathrm{c}+}$ & $4.16 \pm 0.24^{c+}$ & $24.85 \pm 0.80^{\mathrm{b}+}$ & $1.10 \pm 0.15^{\mathrm{c}^{\star \star}}$ \\
\hline IX & $71.92 \pm 6.61^{\mathrm{b}+}$ & $31.26 \pm 2.28^{\mathrm{b}+}$ & $72.15 \pm 3.16^{a+}$ & $4.53 \pm 0.24^{\mathrm{C+}}$ & $23.81 \pm 3.88^{b+}$ & $2.04 \pm 0.52^{b^{\star \star}}$ \\
\hline$x$ & $71.18 \pm 3.16^{\mathrm{C+}}$ & $30.59 \pm 2.99^{b+}$ & $65.00 \pm 6.83^{a+}$ & $4.07 \pm 0.21^{b+}$ & $21.40 \pm 4.28^{\mathrm{b}+}$ & $2.78 \pm 0.61^{a^{\star *}}$ \\
\hline \multicolumn{7}{|c|}{$\begin{array}{l}{ }^{b-} \text { and }^{c-} \text { represent significant decreases at } p<0.001 \text { and } p<0.0001 \text {, respectively, when compared to untreated negative control (Group I) values, while }{ }^{c^{*}} \text { represents a significant increase } \\
\text { at } p<0.0001 \text { when compared to Group I value; }{ }^{a+, b+} \text { and }{ }^{c+} \text { represent significant increases at } p<0.05, p<0.001 \text {, and } p<0.0001 \text {, respectively, when compared to untreated TZM- } \\
\text { intoxicated control (Group V) values, while }{ }^{a^{* *}, b^{* *}} \text { and }{ }^{c^{* *}} \text { represent significant decreases at } p<0.05, p<0.001 \text {, and } p<0.0001 \text {, respectively, when compared to untreated TZM-intoxicated } \\
\text { control (Group V) values. }\end{array}$} \\
\hline \multicolumn{7}{|c|}{$\begin{array}{l}\text { Groups I: untreated normal control; Group II: } 5 \text { mg/kg/day valsartan; Group III: 0.25 mg/kg/day amlodipine; Group IV: } 0.035 \text { mg/kg/day lisinopril; Group V: untreated TZM control; Groups } \\
\text { VI: } 5 \text { mg/kg/day valsartan +2.25 mg/kg/day TZM; Group VII: } 0.25 \text { mg/kg/day am/odipine +2.25 mg/kg/day TZM; Group VIII: 0.035 mg/kg/day lisinopril +2.25 mg/kg/day TZM; Groups IX: } \\
\text { [0.25 mg/kg/day amlodipine +0.035 mg/kg/day lisinopril] + } 2.25 \text { mg/kg/day TZM; Group X: [5 mg/kg/day valsartan +0.035 mg/kg/day lisinopril] + 2.25 mg/kg/day TZM. }\end{array}$} \\
\hline
\end{tabular}

(Group I) (Figure 2). Rats orally pretreated with ADP, LSP, and VAL had no significant alterations in their cardiac caspase-3 levels. However, repeated oral pretreatments with ADP, LSP, VAL and their fixed-dose [(ADP + LSP) and (VAL + LSP)] combinations significantly $(p<0.05)$ attenuated TZM-induced elevation in caspase-3 levels in the treated rats (Figure 2).

Similarly, while oral pretreatments with ADP, LSP and VAL did not induce significant $(p>0.05)$ alterations in the caspase9 level when compared to untreated normal control group (Figure 3), TZM intoxication (Group V) induced profound ( $p$ $<0.05)$ caspase- 9 expression in the treated rat cardiac tissue when compared to the untreated normal control (Group I) (Figure 3). However, this increased caspase-9 expression was effectively $(p<0.05)$ attenuated by oral pretreatments with ADP, LSP, VAL and fixed-dose (ADP + LSP) combination except (VAL + LSP) combination which caused an insignificant $(p>0.05)$ reduction in the cardiac tissue caspase-9 expression (Figure 3).

\section{Amlodipine, Lisinopril, Valsartan and Their Fixed-Dose Combinations on TZM-Treated Cardiac Tissue Caspase-3 Expression}

Caspase- 3 expressions in untreated TZM-intoxicated cardiac tissues (Figures 4E) and cardiac tissues pretreated with VAL, ADP, LSP and their fixed-dose $[(\mathrm{ADP}+\mathrm{LSP})$ and $(\mathrm{VAL}+$ LSP)] combinations are as depicted in Figures 4B-D and F-I, respectively. Untreated TZM-intoxicated cardiac tissue showed enhanced expression of caspase-3 (Figures 4E) compared to normal control group (Figures 4A). Quantification of the immunohistochemical intensity showed profound $(p<0.05)$ increase in intensity score suggesting profound enhanced caspase-3 expression in TZM-treated rats compared with the untreated normal control (Figure 4K). However, there was a significant $(p<$ $0.05)$ decrease in intensity score of TZM-treated rats that were orally pretreated with LSP (Figure $\mathbf{4 H}$ ) and the fixed-dose
$[(\mathrm{ADP}+\mathrm{LSP})($ Figure 4I) and $(\mathrm{VAL}+\mathrm{LSP})($ Figure 4J) $]$ combinations.

\section{Effect of Amlodipine, Lisinopril, Valsartan and Their Fixed-Dose Combinations on TZM-Treated Cardiac Tissue BCL-2 Expression}

The photomicrographs of immunohistochemical staining for BCL-2 expression in cardiac tissues are as shown in Figures 5A-J. While normal rats did not show significant BCL-2 expression (Figures 5A,K), there was a significant $(p<0.0)$ reduction in the BCL-2 expression in the untreated TZMintoxicated rats as indicated in by intensity scores (Figures 5E,K). Similarly, significant $(p<0.05)$ reductions in BCL2 expressions were recorded for rats orally pretreated with ADP (Figures 5G,K) and LSP (Figures 5H,K). However, there was a significant $(p<0.05)$ increase in the BCL2 expression in rats orally pretreated with fixed-dose $[(\mathrm{ADP}+\mathrm{LSP})$ (Figures 5I,K) and $(\mathrm{VAL}+\mathrm{LSP})$ (Figures 5J,K) combinations (Figures 5E,K).

\section{DISCUSSION}

The monoclonal antibody, trastuzumab, not only to improve treatment outcome but also remains the gold standard in the treatment of locoregional and advanced overexpressing HER2 breast cancer with its most notorious off-target side effect being cardiotoxicity since HER2 is involved in myocardial homeostasis (Tocchetti et al., 2012; Hamed et al., 2016). Clinically, TZMinduced cardiotoxicity may manifest as left ventricular dysfunction (Tocchetti et al., 2012), hypertensive crisis (Herrmann et al., 2014), which can decompensate to heart failure, and ultimately cardiac death (Bowles, 2012; Ezaz et al., 2014; Cuomo et al., 2019). Although the exact mechanism(s) of TZM-mediated cardiotoxicity is primarily type II chemotheraphy-related cardiotoxicity (being dose-independent, largely reversible, and 
A

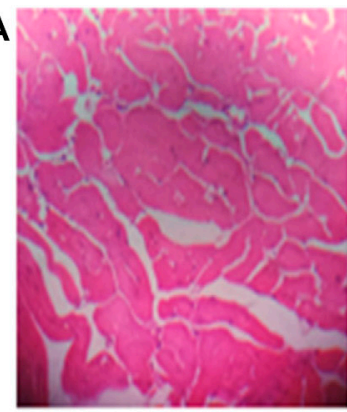

E
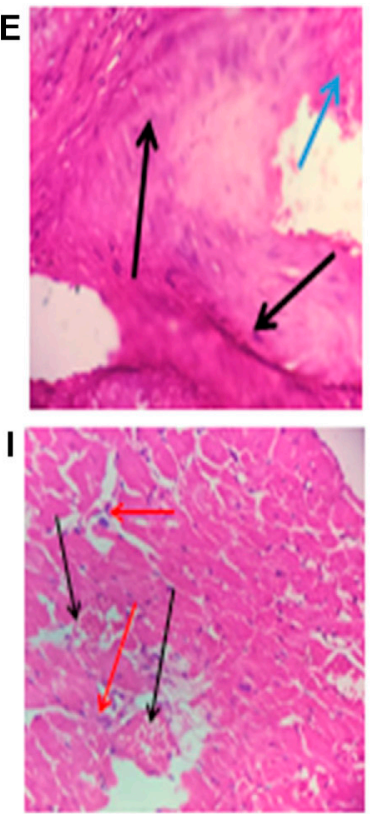

B

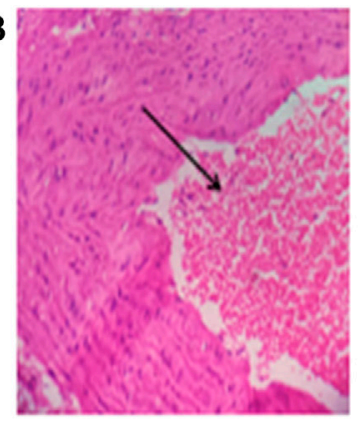

F

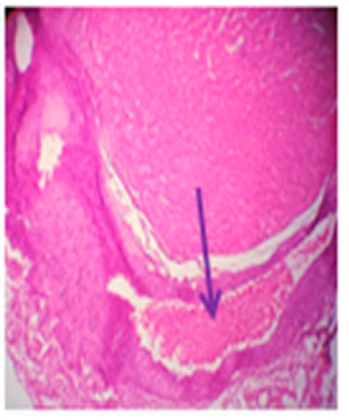

J

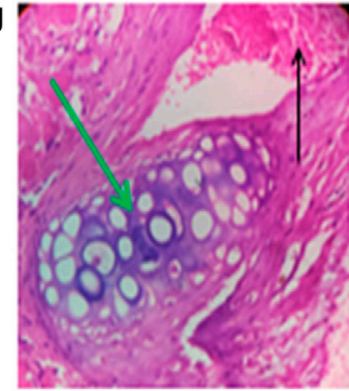

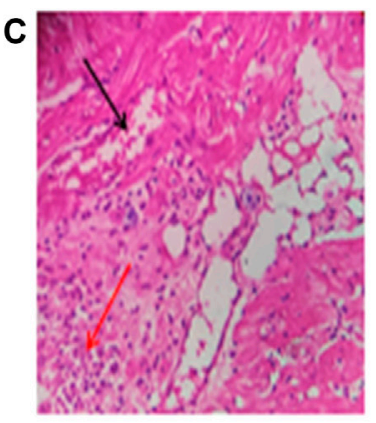

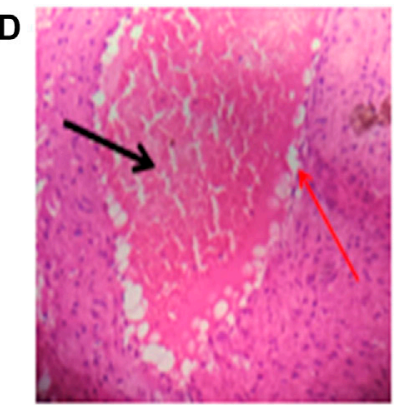

G

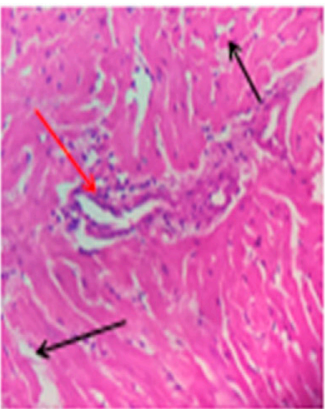

H

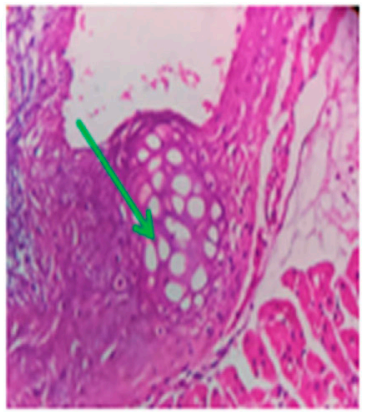

FIGURE 1 | (A) A cross-sectional representative of the rat heart tissue pretreated with $10 \mathrm{ml} / \mathrm{kg} /$ day $/$ p.o. sterile water and $1 \mathrm{ml} / \mathrm{kg} / \mathrm{day} / \mathrm{i}$. p. route of sterile water showing normal cardiac histoarchitecture ( $\times 400$ magnification, hematoxylin-eosin stain). (B) A cross-sectional representative of rat heart pretreated with 5 mg/kg/day/ p.o. VAL dissolved in sterile water showing mild coronary artery congestion (indicated by the thin black arrow) and normal myocardiocytes ( $\times 400$ magnification, hematoxylin-eosin stain). (C) A cross-sectional representative of the rat heart pretreated with $0.25 \mathrm{mg} / \mathrm{kg} / \mathrm{day} / \mathrm{p} . \mathrm{o}$. route ADP dissolved in sterile water showing mild congestion (indicated by the thin black arrow) and lymphocytic infiltration of cardiomyocytes (indicated by the thin red arrow) ( $\times 400$ magnification, hematoxylin-eosin stain). (D) A cross-sectional representative of rat cardiac tissue pretreated with $0.035 \mathrm{mg} / \mathrm{kg} / \mathrm{day} / \mathrm{p}$.o. route LSP dissolved in sterile water showing severe vascular congestion (indicated by the thick black arrow) and diffuse perivascular lymphocytic infiltration (indicated by the thin red arrow) ( $\times 400$ magnification, hematoxylin-eosin stain). (E) A cross-sectional representative of untreated TZM-intoxicated rat cardiac tissue pretreated with $10 \mathrm{ml} / \mathrm{kg} /$ day $/ \mathrm{p} .0$. sterile water showing severe vascular and cardiomyocyte congestion (indicated by the thick black arrow) and intraparenchymal hemorrhage (indicated by the thick blue arrow) ( $\times 400$ magnification,

hematoxylin-eosin stain). (F) A cross-sectional representative of TZM-intoxicated rat cardiac tissue pretreated with 5 mg/kg/day $/ p .0$. VAL showing coronary artery recanalization (indicated by the thick purple arrow) (×100 magnification, hematoxylin-eosin stain). (G) A cross-sectional representative of $T Z M$-intoxicated rat cardiac tissue pretreated with $0.25 \mathrm{mg} / \mathrm{kg} /$ day/p.o. ADP dissolved in sterile water showing mild cardiac vascular congestion (indicated by the thin black arrow) with sparse lymphocytic infiltration of the cardiomyocytes (indicated by the thin red arrow) ( $\times 400$ magnification, hematoxylin-eosin stain). (H) A cross-sectional representative of the TZM-intoxicated cardiac tissue pretreated with $0.035 \mathrm{mg} / \mathrm{kg} /$ day $/$ p.o. LSP dissolved in sterile water showing moderate vascular congestion and cartilaginous metaplasia within the coronary blood vessel wall (indicated by the thick green arrow) ( $\times 400$ magnification, hematoxylin-eosin stain). (I) A cross-sectional representative of TZM-intoxicated rat cardiac tissue pretreated with the fixed dose $0.25 \mathrm{mg} / \mathrm{kg} /$ day $/$ p.o. route ADP +0.035 mg/kg/day $/ p .0$. route LSP combination dissolved in sterile water showing moderate vascular congestion (indicated by the thin black arrow) with sparse lymphocytic infiltration (indicated by the thin red arrow) ( $\times 400$ magnification, hematoxylin-eosin stain). (J) A cross-sectional representative of the TZM-intoxicated rat cardiac tissue pretreated with 5 mg/ $/ \mathrm{kg} / \mathrm{day} / \mathrm{p} .0$. route VAL +0.035 mg/ $\mathrm{kg} / \mathrm{day} /$ p.o. LSP showing mild-to-moderate vascular congestion (indicated by the thin black arrow) and coronary arterial wall cartilaginous metaplasia within the coronary blood vessel wall (indicated by the thick green arrow) (×400 magnification, hematoxylin-eosin stain).

does not produce ultrastructural changes on histological examination) (Hamed et al., 2016) but has been proposed to result from a "dual-hit" mechanism namely: direct inhibition of antiapoptotic pathways and upregulation of angiotensin II which induces apoptosis through $\mathrm{AT}_{1}$ receptor as well activation of NADPH oxidase leading to cell death through mitochondrial dysfunction (Spector and Blackwell, 2009; Zeglinski et al., 2011; Sadek et al., 2017), with resultant increase in reactive oxygen species (ROS) production and inhibition of neuregulin-1 (NRG-1) signaling pathway 


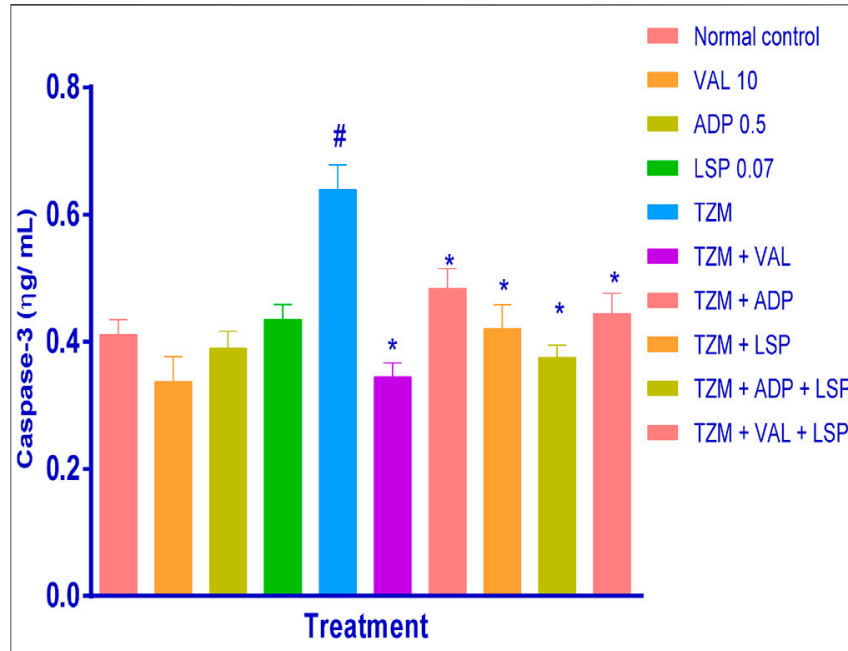

FIGURE2 | Effect of drug treatment on cardiac tissue caspase-3 levels in rats as measured by ELISA. Bar represents mean \pm SEM $(n=4)$, significant difference denoted by \# $p<0.05$ vs. normal control (Group I) or * $p<0.05$ vs. TZM by One-way ANOVA followed by Turkey's post hoc test. Normal control, VAL-valsartan 5 mg/kg/day, ADP-amlodipine 0.25 mg/kg/day, LSPlisinopril $0.035 \mathrm{mg} / \mathrm{kg} /$ day, and TZM-trastuzumab $2.25 \mathrm{mg} / \mathrm{kg} /$ day.

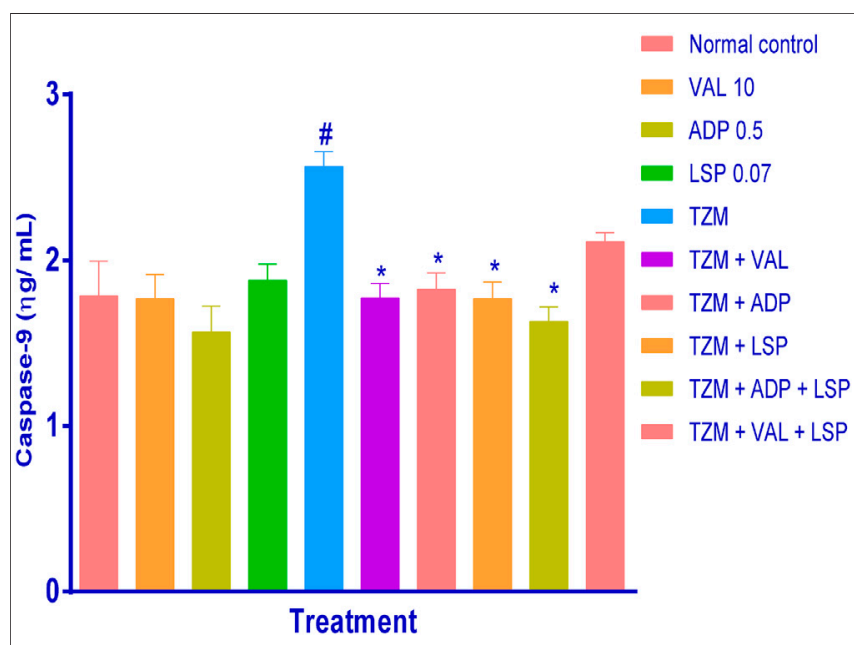

FIGURE 3 | Effect of drug treatment on cardiac tissue caspase-9 levels in rats measured by ELISA. Bar represents mean \pm SEM $(n=4)$, significant difference denoted by \# $p<0.05$ vs. normal control or ${ }^{*} p<0.05$ vs. TZM-only by one-way ANOVA followed by Turkey's post hoc test. Normal control,

VAL-valsartan $5 \mathrm{mg} / \mathrm{kg} /$ day, ADP-amlodipine $0.25 \mathrm{mg} / \mathrm{kg} /$ day, LSP-lisinopril $0.035 \mathrm{mg} / \mathrm{kg}$, and TZM-trastuzumab $2.25 \mathrm{mg} / \mathrm{kg} /$ day.
(Hamed et al., 2016; Sadek et al., 2017). TZM cardiotoxicity is also believed to be related to antibody-dependent and complement-dependent cytotoxicity (Force et al., 2007).

Previous studies have reported the protective role that some classes of antihypertensive agents play in ameliorating TZM- and anthracycline-induced cardiotoxicity (Hahn et al., 2014; Rygiel, 2016; Brown et al., 2020). These classes include cardioselective $\beta_{1^{-}}$ adrenoceptor blockers ( bisoprolol, carvedilol, metoprolol, etc) (Nohria, 2013; Pituskin et al., 2017; Brown et al., 2020), calcium channel blockers (e.g., amlodipine), angiotensin-converting enzyme inhibitors ( lisinopril, enalapril, etc.) (Guglin et al., 2019; Vaduganathan et al., 2019; Brown et al., 2020), and angiotensin receptor blockers (ARBs) (losartan, valsartan, telmisartan, candesartan, etc) (Boekhout et al., 2016; Gulati et al., 2016), although there have been conflicting results of the therapeutic benefits of these antihypertensive classes of drugs (Gujral et al., 2018). In view of these drawbacks, the present study aimed at evaluating the therapeutic potentials of amlodipine, lisinopril, valsartan individually and their fixed-dose combinations in ameliorating $T Z M$-associated cardiotoxicity in experimental rats using biochemical (cardiac enzyme markers, complete lipids profile, cardiac oxidative stress markers, and apoptosis markers), histopathological, and immuhistochemical endpoints.

TZM treatment is known to cause the type of cardiac injury that is characterized by elevated serum cardiac specific biomarkers such as cardiac troponins $\mathrm{I}$ and $\mathrm{T}(c \operatorname{TnI}$ and $c T n T), \mathrm{LDH}$, brain (B-type) natriuretic peptide (BNP), CK-MB (Singh et al., 2015; Ananthan and Lyon, 2020; Demissei et al., 2020), and pro-inflammatory mediators such as interleukin (IL)6, c-reactive protein, myeloperoxidase, galectin-3, and growth differentiation factor-15 (Ananthan and Lyon, 2020; Demissei et al., 2020). In this study, TZM-induced cardiotoxicity was marked by profound elevation in the serum $c T n I$ and LDL, and these elevations were reliably attenuated by ADP, LSP, VAL and their fixed-dose [(ADP + LSP) and (VAL + LSP)] combinations indicating cardioprotective potential of these drugs in TZM-mediated cardiotoxicity. Previous studies, however, have shown LSP and carvedilol to profoundly protect against TZM-mediated serum elevation of these cardiac enzyme markers (Witteles and Bosch, 2015; Guglin et al., 2019). Similar protective effect was reportedly offered by VAL in breast cancer patients on trastuzumab chemotherapy (Al-Hamadi et al., 2018) as well as ADP (Keefe, 2002; Jones et al., 2009; Thomas, 2017), thus, lending support to our findings.

The renin-angiotensin system (RAS) plays a critical role in the development of myocardiac hypertrophy, cardiac failure, and reperfusion injury (Zablocki and Sadoshima 2013; Pinter et al., 2018) and its suppression by angiotensin-converting enzyme inhibitors equally ameliorate heart remodeling process, thereby, prolonging long-term survival time in animal models and humans with cardiac hypertrophy, failure, and reperfusion injury (Iqbal et al., 2008; Akolkar et al., 2015). At the molecular level, angiotensin II effectively down-regulates the actions of the NRG-1/ ErB system (Lemmens et al., 2006), suggesting that the beneficial role of angiotensin-converting enzyme (ACE) inhibition may be related to this effect (Cardinale et al., 2006; Munster et al., 2019). Thus, lisinopril, could be mediating its cardioprotective mechanism in TZM cardiotoxicity via the heart remodeling pathway.

Oxidative and nitrative stress have been implicated in the pathophysiology of TZM-mediated cardiotoxicity through generation of highly toxic reactive oxygen species (ROS) and nitrative species by impeding HER-2 signaling and inhibiting tissue pro-survival effects (Deavali et al., 2012; 

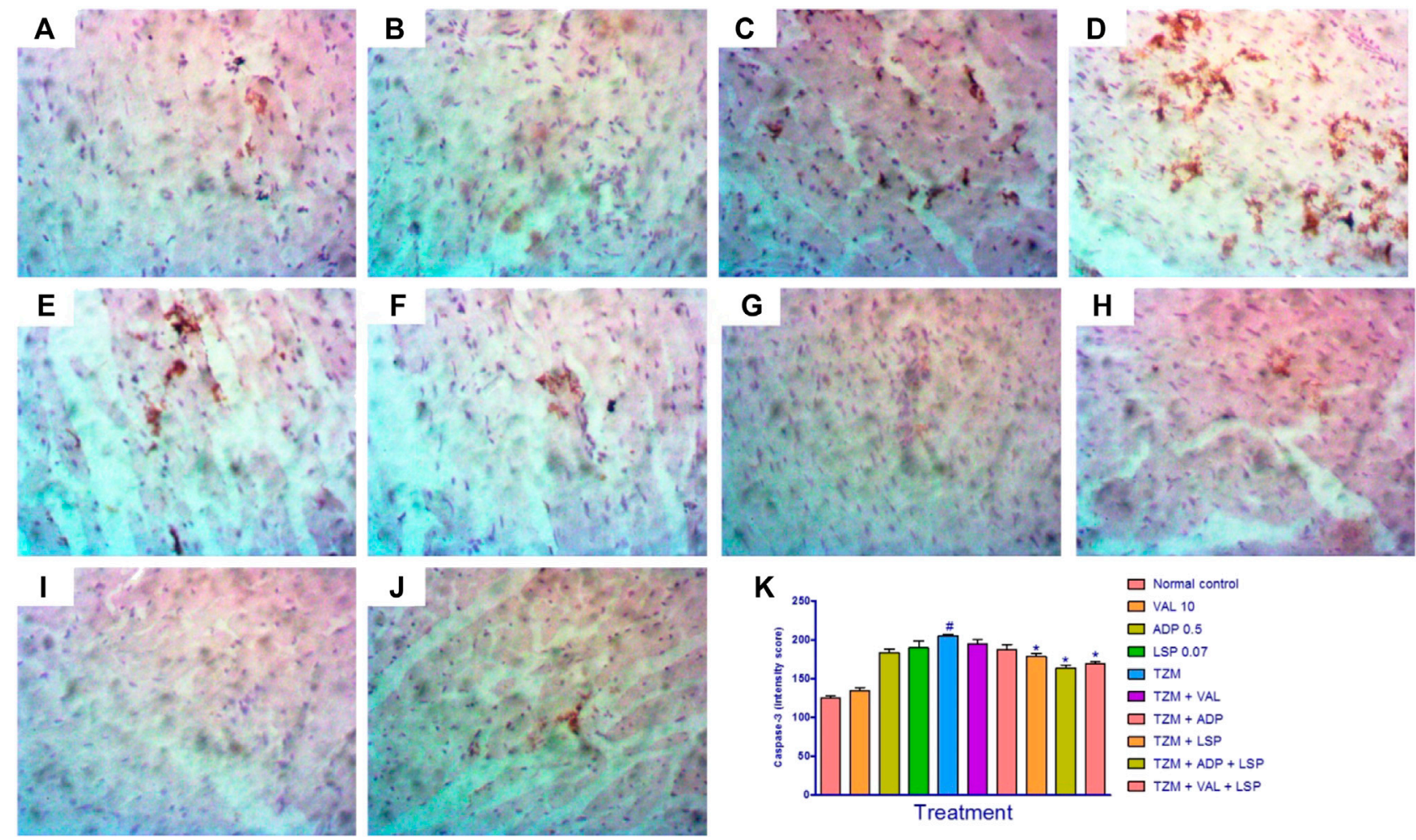

FIGURE 4 | Representative photomicrographs of immunohistochemical expression of caspase-3 in cardiac tissue of rats (magnification $\times 400)$. (A) Normal control, (B) valsartan $10 \mathrm{mg} / \mathrm{kg} /$ day, (C) amlodipine $0.25 \mathrm{mg} / \mathrm{kg} /$ day, (D) lisinopril $0.035 \mathrm{mg} / \mathrm{kg} /$ day, (E) trastuzumab (TZM) $2.25 \mathrm{mg} / \mathrm{kg} /$ day, (F) $T Z M+$ valsartan $5 \mathrm{mg} / \mathrm{kg} / \mathrm{day}$, (G) $T Z M+$ amlodipine $0.25 \mathrm{mg} / \mathrm{kg} /$ day, (H) $T Z M+$ lisinopril $0.035 \mathrm{mg} / \mathrm{kg}$, (I) $T Z M+$ amlodipine + lisinopril, (J) $T Z M+$ valsartan + lisinopril, and (K) intensity score of caspase-3 expression, mean \pm SEM $(n=3)$, and significant difference denoted by $\# p<0.05$ vs. normal control or ${ }^{*} p<0.05$ vs. TZM by one-way ANOVA followed by Turkey's post hoc test.

Mohan et al., 2017; Gorini et al., 2018). TZM is known to interfere with mitochondrial functionality to cause mitochondrial dysfunction, ATP depletion, and inhibiting AMPK and PI3K/Akt pathways (Teppo et al., 2017; Gorini et al., 2018). TZM sets off proapoptotic pathway proteins such as $B a x$ and can trigger the opening of $m P T P$, consequently resulting in mitochondrial dysfunction and ROS accumulation (Gordon et al., 2009). Similarly, TZM also binds to HER-2 and increases proapoptotic Bcl-xS expression while it decreases antiapoptotic Bcl-xL expression (Grazette et al., 2004; Sadek et al., 2017). These result in overwhelming ROS production and reduced ROS scavenging activities with consequent profound inhibition of SOD, CAT, GST, and GPx activities, reduced GSH levels as well as increased MDA levels of TZM-treated tissues (Dirican et al., 2014). The fact that the referred cardiac oxidative stress enzyme activities were profoundly inhibited by the TZM treatment, our finding is, thus, in tandem with other earlier findings (Dirican et al., 2014; Teppo et al., 2017; Gorini et al., 2018). Also, the fact that VAL, LSP, ADP and their fixed-dose combinations profoundly improved the activities of oxidative stress marker enzymes in the treated rats strongly suggest the protective role of these antihypertensive agents in $T Z M$-induced tissue oxidative stress mediated via reduced caspase-3 and caspase-9 production as well as increased antioxidant mechanisms.

Another significant finding of this study is the effect of ADP, LSP, VAL and their fixed-dose combination pretreatments and TZM treatments on serum complete lipid profile. In this study, the fact that repeated TZM treatment was associated with resultant marked hypertriglyceridemia without corresponding hypercholesterolemia is a strong indication that TZM could increase the risk for an adverse cardiovascular event such as angina pectoris, ischemic heart disease, cardiomyopathy, stroke, and heart failure. This assertion is in consonance with previous studies that have reported TZM to increase the risk for coronary artery disease and ischemic heart disease (Rushton et al., 2017; Yuan et al., 2018; Montemurro et al., 2019; Chaturvedi et al., 2020). The fact that ADP, LSP, and VAL pretreatment individually attenuated $T Z M$-associated hypertriglyceridemia is notable and indicate cardioprotective potentials of these drugs although their fixed-dose combinations worsened TZM's potentials for dyslipidemia and increased risk for cardiovascular events. The reason and underlying mechanism(s) for these observations are beyond the scope and cannot be deduced from results of the current study but would be worth exploring in the nearest future.

Atherogenic index of plasma (AIP) is a very reliably crucial index that can be used as a stand-alone index for cardiac risk estimation 

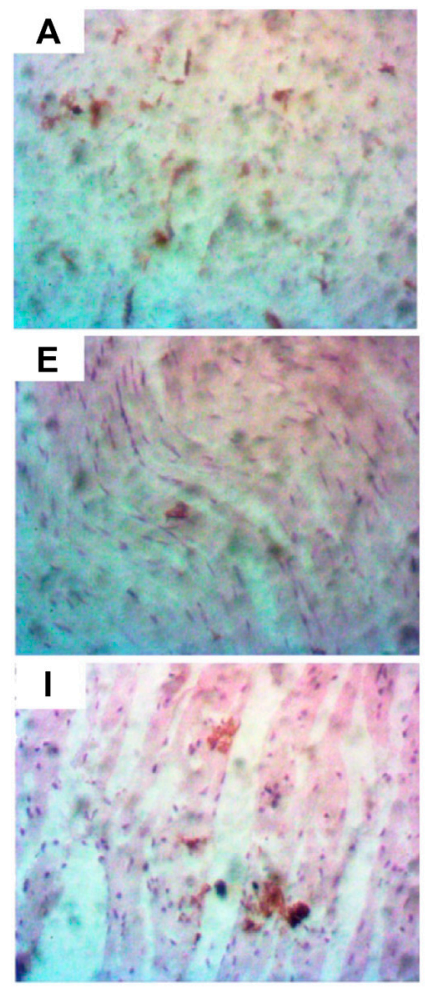
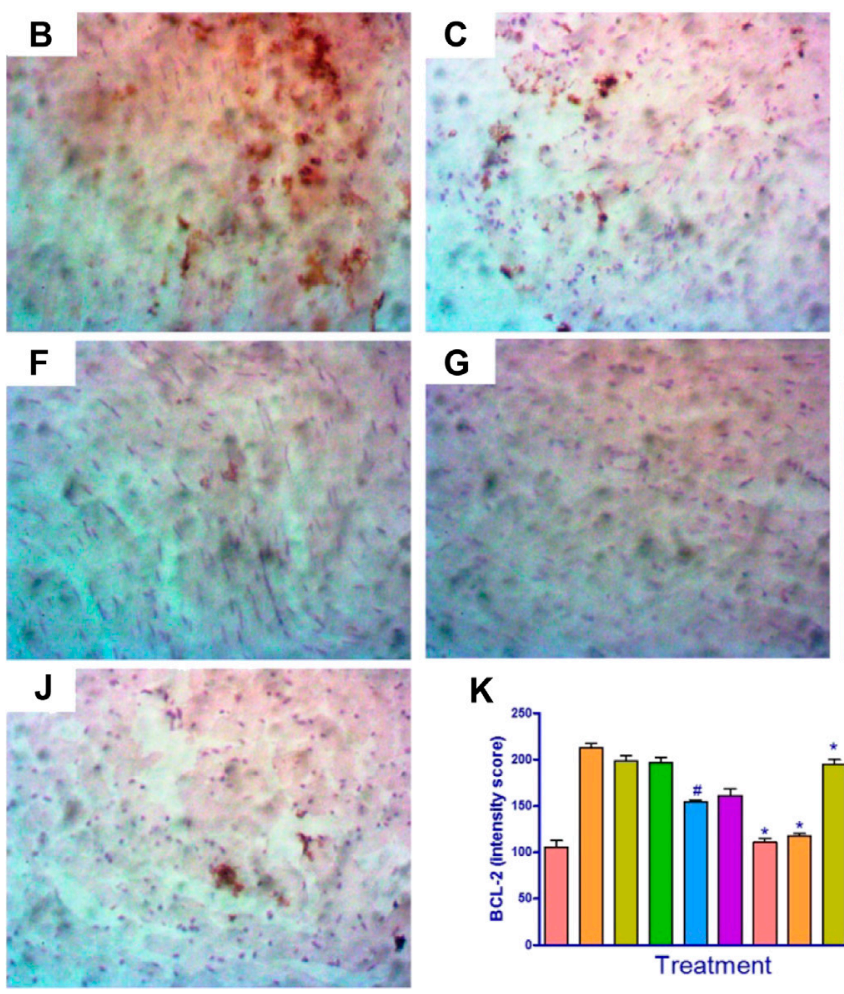

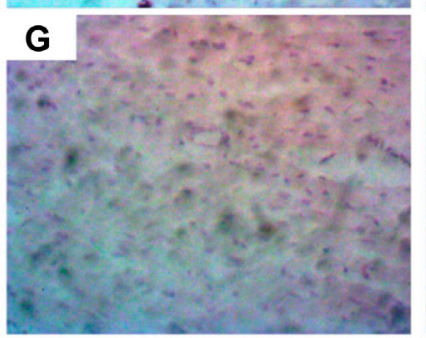

K

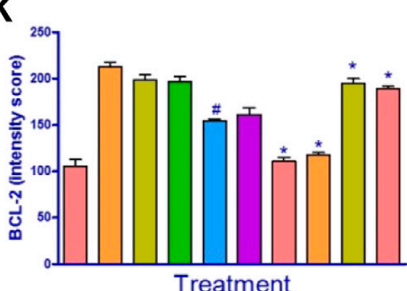

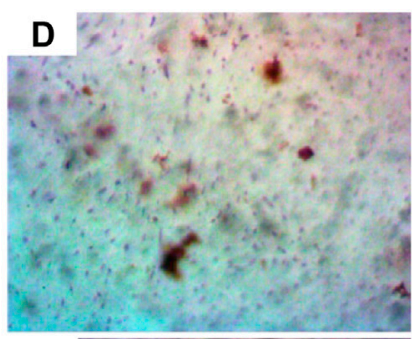

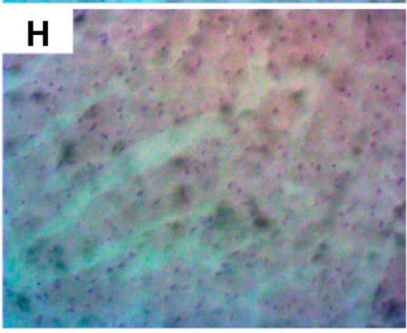

$\square$ Normal control

$\square$ VAL 10

$\square$ ADP 0.5

$\square$ ADP 0.5

口TZM

TZM + VAL

$\square T Z M+A D P$

$\square T Z M+L S P$

口 $T Z M+A D P+L S P$

$\square T Z M+V A L+L S P$

FIGURE 5 | Representative photomicrographs of immunohistochemical expression of BCL-2 in cardiac tissue of rats (magnification $\times 400)$. (A) Normal control, (B) valsartan (VAL) $5 \mathrm{mg} / \mathrm{kg} / \mathrm{day}$, (C) amlodipine (ADP) $0.5 \mathrm{mg} / \mathrm{kg} /$ day, (D) lisinopril (LSP) $0.035 \mathrm{mg} / \mathrm{kg} /$ day, (E) trastuzumab (TZM) $2.25 \mathrm{mg} / \mathrm{kg} / \mathrm{day}$, (F) TZM + valsartan $5 \mathrm{mg} / \mathrm{kg} /$ day, (G) $T Z M+$ amlodipine $0.25 \mathrm{mg} / \mathrm{kg} /$ day, (H) $T Z M+$ lisinopril $0.035 \mathrm{mg} / \mathrm{kg} /$ day, (I) $T Z M+$ amlodipine + lisinopril, (J) $T Z M+$ valsartan + lisinopril, and (K) intensity score of BCL-2 expression, mean \pm SEM $(n=3)$, and significant difference denoted by ${ }^{\#} p<0.05$ vs. normal control or ${ }^{*} p<0.05$ vs. TZM by one-way ANOVA followed by Turkey's post hoc test.

and changes in the levels of any lipid profile predisposes to atherosclerosis and its associated complication (Kanthe et al., 2012; Khazaal, 2013). It is defined as logarithm $\left[\log _{10}\right]$ of the ratio of plasma concentration of TG to HDL-c and is strongly correlated with cardiovascular risks and as such could be considered an adjunct over the individual lipid profile (Dobiasova, 2004; Nansseu et al., 2016). AIP is, thus, considered the best determinant for fractionated esterification rate of HDL-c and more useful than routine lipid parameters (Bo et al., 2018). The AIP value of $<0.11$ is considered low risk, while AIP values of $0.11-0.21$ and $>0.21$ are considered intermediate risk and increased risk, respectively. The fact that the AIP estimates for the fixed-dose combinations of ADP + LSP and VAL + LSP were higher than 0.21, strongly indicates that these fixed-dose combinations could further increase the risk for $T Z M$-induced atherosclerosis although previous studies have reported TZM to be atherogenic in nature (Yu et al., 2015; Di Lisi et al., 2017; Yersal et al., 2018). Conversely, the fact that VAL, ADP, and LSP profoundly decreased the AIP value to less than 0.11 is another strong indication that these drugs individually could be attenuating TZM-induced atherosclerosis. This finding is, thus, in complete agreement with an earlier study that reported amlodipine and valsartan to improve AIP of patients with end-stage chronic renal disease on hemodialysis and peritoneal dialysis (Erdur et al., 2013).
The effect of TZM on weight gain pattern is also significant. Repeated TZM treatment was associated with profound weight loss. Again, this finding is in tandem with previous studies that have reported similar weight loss in patients on TZM treatment (Hajjaji et al., 2014) although the $T Z M$ has been reported to have variable effects of body weight pattern in cancer patients on TZM treatment (Winkels et al., 2014; Reijers and Burggraaf, 2015; Ginzac et al., 2020). However, oral pretreatment with ADP, LSP, VAL and their fixed-dose combinations further induced weight reduction in the face of TZM chemotherapy highlighting the weight loss potential of these antihypertensive drugs and their fixed-dose combinations which were probably mediated via plasma norepinephrine, insulin, and leptin inhibitions, and these were previously reported in the obese hypertensive patients on prolonged amlodipine, lisinopril, valsartan and fixed-dose amlodipine-valsartan combination use (Masuo et al., 2001; Villecco et al., 2004).

TZM is known to cause related cardiac dysfunction without corresponding histoarchitectural distortion of the myocytes (Jones et al., 2009) although TZM was recently reported to induce severe vascular congestion and associated microthrombi formation (Olorundare et al., 2020) in treated experimental rats which the present study is in tandem with. 
However, the fact that these histopathological changes were profoundly improved by ADP, VAL, and fixed-dose (ADP + $\mathrm{VAL}$ ) combination pretreatments strongly suggests the cardioprotective potential of these drugs. Another recognizable finding of this study is the histological finding of coronary artery cartilaginous metaplasia which was a prominent cardiac histopathological feature found in rat hearts pretreated with LSP- and fixed-dose VAL-LSP combination. Vascular cartilaginous/osseous metaplasia, which is often associated with the presence of arterial chondrocytes that express type II collagen, is known to be part of the progression of mineralization or atherosclerotic lesion (Fitzpatrick et al., 2003; Nguyen et al., 2012). It also provides evidence of cardiac extracellular matrix remodeling for post-infarcted heart and may constitute a supplemental factor for heart failure when it calcifies (Manole et al., 2019; Carreon et al., 2020). Cartilaginous metaplasia is considered a potential great risk for arterial wall calcification associated with the atherosclerotic plaque (Qiao et al., 1995). Thus, the marked presence of coronary artery cartilaginous metaplasia as seen in cardiac tissues treated with the fixed-dose valsartan-lisinopril (VAL + LSP) combination strongly suggests either vascular remodeling of the TZM-mediated endothelial injury or coronary artery atheromatous plaque formation. However, the latter appears to be more likely as the histological finding of coronary artery cartilaginous metaplasia was corroborated by the profound increases in the AI and CRI values. This finding, thus, suggests that the fixed-dose valsartan-lisinopril combination could likely increase the risk for coronary artery atheromatous plaque formation in patients on TZM treatment.

In conclusion, findings of this study highlight the promising therapeutic potentials of the antihypertensives-amlodipine, lisinopril, valsartan, and their fixed-dose combinations as repurposed therapeutics in the management of TZM-induced cardiotoxicity, partly mediated via antiapoptotic and oxidative stress inhibition mechanisms. However, lisinopril and fixed-dose valsartan-lisinopril combination should be used with caution in cancer patients already on trastuzumab therapy as they could predispose to coronary artery atheromatous plaque formation.

\section{REFERENCES}

Akolkar, G., Bhullar, N., Bews, H., Shaikh, B., Premecz, S., Bordun, K. A., et al. (2015). The role of renin angiotensin system antagonists in the prevention of doxorubicin and trastuzumab induced cardiotoxicity. Cardiovasc. Ultrasound. 13, 18. doi:10.1186/s12947-015-0011-x

Al-Hamadi, N. A., Al-Sabri, I., Aldujele, A. B., Al-Fatlawi, S. J., and Allebban, Z. (2018). Valsartan attenuates cardiotoxicity in breast cancer patients after chemotherapy. Cancer Sci. Ther. 10 (5), 105-109. doi:10.4172/19485956.1000526

Alhamdani, F. Y. (2009). Possible beneficial effects of amlodipine, lisinopril, and their combination on lipid profile in hypertensive patients. Iraqi J. Vet. Med. 33 (2), 126-137. doi:10.11648/j.ajcem.20160405.16

\section{DATA AVAILABILITY STATEMENT}

The raw data supporting the conclusions of this article will be made available by the authors, without undue reservation.

\section{ETHICS STATEMENT}

The animal study was reviewed and approved by University Ethics and Research Grant Committee, University of Ilorin with the UERC approval number: UERC/ASN/2020/2027 given.

\section{AUTHOR CONTRIBUTIONS}

All authors read through and approved submission of this article. OEO designed the experimental protocol for this study and was involved in the manuscript writing. AAA supervised the research, analyzed data, and wrote the manuscript; AOA is an M.Sc. student in OEO's Laboratory who performed the laboratory research. OAA is a $\mathrm{PhD}$ student in OEO's Laboratory and assisted AMA in the ELISA assays of the cardiac tissues. IIO prepared the cardiac tissue slides while SSS and AIM independently read and interpreted the prepared histology slides of the treated cardiac tissues. RMA, JMN, and PAC are our collaborators in the United States who read through the manuscript.

\section{ACKNOWLEDGMENTS}

The authors deeply appreciate the technical assistance provided by the laboratory manager, Dr Sarah John-Olabode and other staff of the Laboratory Services, AFRIGLOBAL MEDICARE, Mobolaji Bank Anthony Branch Office, Ikeja, Lagos, Nigeria, in assaying for the serum cardiac biomarkers and lipid profile. Similarly, the technical support of staff of LASUCOM Animal House, for the care of the Experimental Animals used for this study and Mr. Sunday O. Adenekan of BIOLIFE CONSULTS in the area of oxidative stress markers analysis are much appreciated. The technical expertise of $\mathrm{Dr}$ Theophilus Aghogho Jarikre, Department of Veterinary Pathology, Faculty of Veterinary Medicine, University of Ibadan in the area of immunohistochemical staining, is also deeply appreciated.

Alladi, S., and Shanmugasundaram, K. R. (1989). Induction of hypercholesterolemia by supplementing soy protein with acetate generating amino acids. Nutr. Rep. Int. 40, 893-899.

Ananthan, K., and Lyon, A. R. (2020). The role of biomarkers in cardio-oncology. J. Cardiovasc. Transl. Res. 13, 431-450. doi:10.1007/s12265-020-10042-3

Barthur, A., Brezden-Masley, C., Connelly, K. A., Dhir, V., Chan, K. K. W., Haq, R., et al. (2017). Longitudinal assessment of right ventricular structure and function by cardiovascular magnetic resonance in breast cancer patients treated with trastuzumab: a prospective observational study. J. Cardiovasc. Magn. Reson. 19, 44. doi:10.1186/s12968-017-0356-4

Blackwell, K. L., Burstein, H. J., Storniolo, A. M., Rugu, H., Sledge, G., Koehler, M., et al. (2010). Randomized study of lapatinib alone or in combination with trastuzumab in women with ErbB2-positive, trastuzumab-refractory metastatic breast cancer. J. Clin. Oncol. 28, 1124-1130. 
Blanter, J. B., and Frishman, W. H. (2019). The preventive role of angiotensin converting enzyme inhibitors/angiotensin-II receptor blockers and $\beta$-adrenergic blockers in anthracycline- and trastuzumab-induced cardiotoxicity. Cardiol. Rev. 27 (5), 256-259. doi:10.1097/CRD.0000000000000252

Bo, M. S., Cheah, W. L., Lwin, S., Moe Nwe, T., Win, T. T., and Aung, M. (2018). Understanding the relationship between atherogenic index of plasma and cardiovascular disease risk factors among staff of an University in Malaysia. J. Nutr. Metab. 2018, 7027624. doi:10.1155/2018/7027624

Boekhout, A. H., Gietema, J. A., Milojkovic Kerklaan, B., van Werkhoven, E. D., Altena, R., Honkoop, A., et al. (2016). Angiotensin II-receptor inhibition with candesartan to prevent trastuzumab-related cardiotoxic effects in patients with early breast cancer: a randomized clinical trial. JAMA Oncol. 2, 1030-7. doi:10. 1001/jamaoncol.2016.1726

Bowles, E. J. (2012). Risk of heart failure in breast cancer patients after anthracycline and trastuzumab treatment: a retrospective cohort study. J. Natl. Cancer Inst. (Bethesda). 104, 1293-1305. doi:10.1093/jnci/djs317

Bubnova, M., Aronov, D., and Vygodin, V. (2019). Effects of the combinations of amlodipine with lisinopril or a carvedilol in patients with arterial hypertension and obesity. J. Hypertens. 37, e173-e174. doi:10.1097/01.hjh.0000572224.73513.a7

Buege, J. A., and Aust, S. D. (1978). Microsomal lipid peroxidation. Methods Enzymol. 52, 302-310. doi:10.1016/s0076-6879(78)52032-6

Calleja, A., Poulin, F., Khorolsky, C., Shariat, M., Bedard, P. L., Amir, E., et al. (2015). Right ventricular dysfunction in patients experiencing cardiotoxicity during breast cancer therapy. J. Oncol. 2015, 609194. doi:10.1155/2015/609194

Cardinale, D., Colombo, A., Sandri, M. T., Lamantia, G., Colombo, N., Civelli, M., et al. (2006). Prevention of high-dose chemotherapy-induced cardiotoxicity in high-risk patients by angiotensin-converting enzyme inhibition. Circulation 114, 2474-2481. doi:10.1161/CIRCULATIONAHA.106.635144

Carreon, C. K., Sanders, S. P., and Ashworth, M. T. (2020). Chondroid and osseous metaplasia of the central fibrous body in adolescent hearts with mutations in TNNI3 and TNNT2 genes. Pediatr. Dev. Pathol. 7, 21. doi:10.1177/1093526620937572

Chaturvedi, S., Garikapati, A., Ansari, I., Bagga, C., and Kumar, S. (2020). Trastuzumab induced cardiomyopathy with cerebellar stroke: double trouble. Med. Sci. 24 (104), 2424-2427. doi:10.1158/1538-7445.am2016-lb-306

Corremans, R., Adão, R., De Keulenaer, G. W., Leite-Moreira, A. F., and Brás-Silva, C. (2019). Update on pathophysiology and preventive strategies of anthracycline-induced cardiotoxicity. Clin. Exp. Pharmacol. Physiol. 46, 204-215. doi:10.1111/1440-1681.13036

Cuomo, A., Rodolico, A., Galdieri, A., Russo, M., Campi, G., Franco, R., et al. (2019). Heart failure and cancer: mechanisms of old and new cardiotoxic drugs in cancer patients. Card. Fail. Rev. 5 (2), 112-118. doi:10.15420/cfr.2018.32.2

Deavall, D. G., Martin, E. A., Horner, J. M., and Roberts, R. (2012). Drug-induced oxidative stress and toxicity. J. Toxicol. 2012, 645460. doi:10.1155/2012/ 645460

Demissei, B. G., Hubbard, R. A., Zhang, L., Smith, A. M., Sheline, K., McDonald, C., et al. (2020). Changes in cardiovascular biomarkers with breast cancer therapy and associations with cardiac dysfunction. JAHA. 14, 54. doi:10.1161/JAMA. 119.014708

Di Lisi, D., Madonna, R., Zito, C., Bronte, E., Badalamenti, G., Parrella, P., et al. (2017). Anticancer therapy-induced vascular toxicity: VEGF inhibition and beyond. Int. J. Cardiol. 227, 11-17. doi:10.1016/j.ijcard.2016.11.174

Dirican, A., Levent, F., Alacacioglu, A., Kucukzeybek, Y., Varol, U., Kocabas, U., et al. (2014). Acute cardiotoxic effects of adjuvant trastuzumab treatment and its relation to oxidative stress. Angiology 65, 944-949. doi:10.1177/ 0003319714523112

Dobiásová, M., and Frohlich, J. (2001). The plasma parameter log (TG/HDL-c) as an atherogenic index: correlation with lipoprotein particle size and esterification rate in apoB-lipoprotein-depleted plasma (FER(HDL)). Clin. Biochem. 34, 583-588. doi:10.1016/s0009-9120(01)00263-6

Dobiasova, M. (2004). Atherogenic index of plasma [ $\log$ (triglycerides/HDLcholesterol)]: theoretical and practical implications. Clin. Chem. 50, 1113-1115. doi:10.1373/clinchem.2004.033175

Erdur, M. F., Tonbul, H. Z., Ozbiner, H., Ozcicek, A., Ozcicek, F., Akbas, E. M., et al. (2013). The relationship between atherogenic index of plasma and epicardial adipose tissue in hemodialysis and peritoneal dialysis patients. Ren. Fail. 35 (9), 1193-1198. doi:10.3109/0886022X.2013. 823826
Ezaz, G., Long, J. B., Gross, C. P., and Chen, J. (2014). Risk prediction model for heart failure and cardiomyopathy after adjuvant trastuzumab therapy for breast cancer. J Am Heart Assoc. 3, e000472. doi:10.1161/JAHA.113.000472

Fang, K., Zhang, Y., Liu, W., and He, C. (2020). Effects of angiotensin-converting enzyme inhibitor/angiotensin receptor blocker use on cancer therapy-related cardiac dysfunction: a meta-analysis of randomized controlled trials. Heart Fail. Rev. 26 (1), 101-109. doi:10.1007/s10741-019-09906-x

Fitzpatrick, L. A., Turner, R. T., and Ritman, E. R. (2003). Endochondral bone formation in the heart: a possible mechanism of coronary calcification. Endocrinology 144 (6), 2214-2219. doi:10.1210/en.2002-0170

Force, T., Krause, D. S., and van Etten, R. A. (2007). Molecular mechanisms of cardiotoxicity of tyrosine kinase inhibition. Nat. Rev. Canc. 7, 332-344. doi:10. 1038/nrc2106

Gibo, T., Sekiguchi, N., Gomi, D., Noguchi, T., Fukushima, T., Kobayashi, T., et al. (2019). Targeted therapy with trastuzumab for epidermal growth factor receptor 2 (HER2)-positive advanced salivary duct carcinoma: a case report. Mol. Clin. Oncol. 11, 111-115. doi:10.3892/mco.2019.1875

Ginzac, A., Barres, B., Chanchou, M., Gadéa, E., Molnar, I., Merlin, C., et al. (2020). A decrease in brown adipose tissue activity is associated with weight gain during chemotherapy in early breast cancer patients. BMC Canc. 20, 96. doi:10.1186/ s12885-020-6591-3

Gordon, L. I., Burke, M. A., Singh, A. T., Prachand, S., Lieberman, E. D., Sun, L., et al. (2009). Blockade of the erbB2 receptor induces cardiomyocyte death through mitochondrial and reactive oxygen species-dependent pathways. J. Biol. Chem. 284 (4), 2080-2087. doi:10.1074/jbc.M804570200

Gorini, S., De Angelis, A., Berrino, L., Malara, N., Rosano, G., and Ferraro, E. (2018). Chemotherapeutic drugs and mitochondrial dysfunction: focus on doxorubicin, trastuzumab, and sunitinib. Oxid. Med. Cell. Longev. 2018, 7582730. doi:10.1155/2018/7582730

Grazette, L. P., Boecker, W., Matsui, T., Semigran, M., Force, T. L., Hajjar, R. J., et al. (2004). Inhibition of ErbB2 causes mitochondrial dysfunction in cardiomyocytes: implications for herceptin-induced cardiomyopathy. J. Am. Coll. Cardiol. 44 (11), 2231-2238. doi:10.1016/j.jacc.2004.08.066

Guglin, M., Krischer, J., Tamura, R., Fink, A., Bello-Matricaria, L., McCaskillStevens, W., et al. (2019). Randomized trial of lisinopril versus carvedilol to prevent trastuzumab cardiotoxicity in patients with breast cancer. J. Am. Coll. Cardiol. 73 (22), 2859-2868. doi:10.1016/j.jacc.2019.03.495

Gujral, D. M., Lloyd, G., and Bhattacharyya, S. (2018). Effect of prophylactic betablocker or ACE inhibitor on cardiac dysfunction \& heart failure during anthracycline chemotherapy \pm trastuzumab. Breast $37,64-71$. doi:10.1016/j. breast.2017.10.010

Gulati, G., Heck, S. L., Ree, A. H., Hoffmann, P., Schulz-Menger, J., Fagerland, M. W., et al. (2016). Prevention of cardiac dysfunction during adjuvant breast cancer therapy (PRADA): a $2 \times 2$ factorial, randomized, placebo-controlled, double-blind clinical trial of candesartan and metoprolol. Eur. Heart J. 37, 1671-1680. doi:10.1093/eurheartj/ehw022

Guo, S., Tse, G., and Liu, T. (2020). Protective strategies to prevent trastuzumabinduced cardiotoxicity. Lancet 395 (10223), 491-492. doi:10.1016/S01406736(19)32549-8

Hadwan, M. H. (2018). Simple spectrophotometric assay for measuring catalase activity in biological tissues. BMC Biochem. 19, 7.

Hahn, V. S., Lenihan, D. J., and Ky, B. (2014). Cancer therapy-induced cardiotoxicity: basic mechanisms and potential cardioprotective therapies. J Am Heart Assoc. 3, e000665. doi:10.1161/JAHA.113.000665

Hajjaji, N., Chocteau, D., Gerard, S., and Orgerie, M. B. (2014) . "Relationship between weight change and response to trastuzumab-based neoadjuvant chemotherapy among women with operable HER2 overexpressing breast cancer." in Proceedings of the 105th annual meeting of the American association for cancer research; 2014 apr 5-9. San Diego, CA: AACR; Cancer Research.

Hamed, R. H., Salim, K., Alzahrani, A., and Elsamany, S. (2016). Cardiotoxicity of the adjuvant trastuzumab in a Saudi population: clinical experience of a single institution. Forum Clin. Oncol. 7 (2), 1-6. doi:10.1515/fco-2016-0007

Herrmann, J., Herrmann, S. M., and Haddad, T. C. (2014). New-onset heart failure in association with severe hypertension during trastuzumab therapy. Mayo Clin. Proc. 89 (12), 1734-1739. doi:10.1016/j.mayocp.2014.08.011

Hidalgo, S., Albright, C. A., and Wells, G. L. (2013). A case of trastuzumab-associated cardiomyopathy presenting as an acute coronary syndrome: acute trastuzumab cardiotoxicity. Case Rep. Cardiol. 2013, 473979. doi:10.1155/2013/473979 
Iqbal, M., Dubey, K., Anwer, T., Ashish, A., and Pillai, K. K. (2008). Protective effects of telmisartan against acute doxorubicin-induced cardiotoxicity in rats. Pharmacol. Rep. 60, 382-390. doi:10.3109/00498254.2015. 1034223

Jahangir, E., Harinstein, M. E., Murthy, V. L., and Moslehi, J. (2020). The forgotten right ventricle in cardio-oncology. J. Nucl. Cardiol. 27, 2164-2166. doi:10.1007/ s12350-019-01602-5

Jones, A. L., Barlow, M., Barrett-Lee, P., Canney, P. A., Gilmour, I. M., Robb, S. D., et al. (2009). Management of cardiac health in trastuzumab-treated patients with breast cancer: updated United Kingdom National Cancer Research Institute recommendations for monitoring. Br. J. Canc. 100, 684-692. doi:10.1038/sj.bjc.6604909

Kanthe, P. S., Patil, B. S., Shrilaxmi, B., Deshpande, A., Shaikh, G. B., and Aithala, M. (2012). Atherogenic index as a predictor of cardiovascular risk among women with different grades of obesity. Int. J. Collab. Res. Intern. Med. Public Health. 4 (10), 1767-1774. doi:10.2174/1573397116666201007123403

Keefe, D. L. (2002). Trastuzumab-associated cardiotoxicity. Cancer 95 (7), 1592-1600. doi:10.1002/cncr.10854

Khazaal, M. S. (2013). Atherogenic index of plasma as a parameter in predicting cardiovascular risk in males compared to the conventional dyslipidemic indices. Karbala J. Med. 6, 1506-1531. doi:10.26226/morressier.5785edc9d462b80296c999e0

Lameire, N. (2014). Nephrotoxicity of recent anti-cancer agents. Clin. Kidney J. 7 (1), 11-22. doi:10.1093/ckj/stt135

Lemmens, K., Segers, V. F., Demolder, M., and De Keulenaer, G. W. (2006). Role of neuregulin-1/ErbB2 signaling in endothelium-cardiomyocyte cross-talk. J. Biol. Chem. 281, 19469-19477. doi:10.1074/jbc.M600399200

Locatelli, F., Del Vecchio, L., Andrulli, S., and Colzani, S. (2002). Role of combination therapy with ACE inhibitors and calcium channel blockers in renal protection. Kidney Int. Suppl. 62 (82), S53-S60. doi:10.1046/j.1523-1755. 62.s82.11.x

Ma, Y-X., Bai, F., Qin, F., Li, J., Liu, N., Li, D-P., et al. (2019). Beta-blockers for the primary prevention of anthracycline-induced cardiotoxicity: a meta-analysis of randomized controlled trials. BMC Pharmacol. Toxicol. 20, 18 doi:10.1186/ s40360-019-0298-6

Mandaliya, H., Baghi, P., Prawira, A., and George, M. K. (2015). A rare case of paclitaxel and/or trastuzumab induced acute hepatic necrosis. Case Rep. Oncol. Med. 22, 825603 doi:10.1155/2015/825603

Manole, C. G., Marinescu, B. G., and Marta, D., (2019). Areas of cartilaginous and osseous metaplasia after experimental myocardial infarction in rats. Anat. Rec. 302 (6), 947-953. doi:10.1002/ar.24010

Maurea, M., Johnson, C., and Dent, S. (2017). Trastuzumab-induced cardiotoxicity: testing a clinical risk score in a real-world cardio-oncology population. Curr. Oncol. 24 (3), 176-180. doi:10.3747/co.24.3349

Menne, J., Farsang, C., Deák, L., Klebs, S., Meier, M., Handrock, R., et al. (2008). Valsartan in combination with lisinopril versus the respective high dose monotherapies in hypertensive patients with microalbuminuria: the VALERIA trial. J. Hypertens 26 (9), 1860-1867. doi:10.1097/HJH. 0b013e32830508aa

Mohan, N., Jiang, J., Dokmanovic, M., and Wu, W. J. (2018). Trastuzumabmediated cardiotoxicity: current understanding, challenges, and frontiers. Antib. Ther. 1 (1), 13-17. doi:10.1093/abt/tby003

Mohan, N., Jiang, J., and Wu, W. J. (2017). Implications of autophagy and oxidative stress in trastuzumab-mediated cardiac toxicities. Austin Pharmacol. Pharm. 2 (1), 1005. doi:10.1158/1538-7445.am2016-lb-306

Montemurro, F., Ellis, P., Anton, A., Wuerstlein, R., Delaloge, S., Bonneterre, J., et al. (2019). Safety of trastuzumab emtansine (T-DM1) in patients with HER2positive advanced breast cancer: primary results from the KAMILLA study cohort 1. Eur. J. Canc. 109, 92-102. doi:10.1016/j.ejca.2018.12.022

Munster, P., Krischer, J., Tamura, R., Fink, A., Bello-Matricaria, L., and Guilin, M. (2019). A randomized community-based trial of an angiotensin converting enzyme inhibitor, lisinopril or a beta blocker, carvedilol for the prevention of cardiotoxicity in patients with early stage HER2-positive breast cancer receiving adjuvant trastuzumab. Cancer Res. 79 (4 Suppl. l) doi:10.1158/1538-7445. SABCS18-GS5-01

Naidu, M. U., Usha, P. R., and Rao, T. R. (2000). Evaluation of amlodipine, lisinopril, and a combination in the treatment of essential hypertension. Postgrad. Med. J. 76, 350-353.
National Research Council (US) (2011). Committee for the update of the Guide for the care and use of laboratory animals Guide for the care and use of laboratory animals. Washington, D.C., U.S.A: The National Academies Press.

Nguyen, N., Naik, V., and Speer, M. Y. (2012). Diabetes mellitus accelerates cartilaginous metaplasia and calcification in atherosclerotic vessels of LDLr mutant mice. Cardiovasc. Pathol. 22 (2), 167-175. doi:10.1016/j. carpath.2012.06.007

Nicolescu, K., Mikami, H., Ogihara, T., and Tuck, M. L. (2001). Weight reduction and pharmacologic treatment in obese hypertensives. Am. J. Hypertens 14 (6), 530-538. doi:10.1016/s0895-7061(00)01279-6

Nohria, A. (2013). $\beta$-Adrenergic blockade for anthracycline- and trastuzumab-induced cardiotoxicity: is prevention better than cure? Circ. Heart Fail. 6 (3), 358-361. doi:10.1161/CIRCHEARTFAILURE. 113.000267

Olorundare, O., Adeneye, A., Akinsola, A., Soyemi, S., Mgbehoma, A., Okoye, I. et al. (2020). African vegetables (Clerodendrum volubile leaf and Irvingia gabonensis seed extracts) effectively mitigates trastuzumab-induced cardiotoxicity in Wistar rats. Oxid. Med. Cell. Longev. 14, 15-19. doi:10. $1155 / 2020 / 9535426$

Onitilo, A. A., Engel, J. M., and Stankowski, R. V. (2014). Cardiovascular toxicity associated with adjuvant trastuzumab therapy: prevalence, patient characteristics, and risk factors. Ther. Adv. Drug Saf. 5 (4), 154-166. doi:10. $1177 / 2042098614529603$

Paoletti, F., Aldinucci, D., Mocali, A., and Caparrini, A. (1986). A sensitive spectrophotometric method for the determination of superoxide dismutase activity in tissue extracts. Anal. Biochem. 154 (2), 536-541.

Pinter, M., Kwanten, W. J., and Jain, R. K. (2018). Renin-angiotensin system inhibitors to mitigate cancer treatment-related adverse events. Clin. Cancer Res. 24 (16), 3803-3812. doi:10.1158/1078-0432.CCR-18-0236

Pituskin, E., Mackey, J. R., Koshman, S., Jassal, D., Pitz, M., Haykowsky, M. J., et al. (2017). Multidisciplinary approach to novel therapies in cardio-oncology research (MANTICORE 101-breast): a randomized trial for the prevention of trastuzumab-associated cardiotoxicity. J. Clin. Oncol. 35, 870-877. doi:10.1200/JCO.2016.68.7830

Poon, K. A., Flagella, K., Beyer, J., Tibbitts, J., Kaur, S., Saad, O., et al. (2013). Preclinical safety profile of trastuzumab emtansine (T-DM1): mechanism of action of its cytotoxic component retained with improved tolerability. Toxicol. Appl. Pharmacol. 273, 298-313. doi:10.1016/j.taap.2013.09.003

Porta, C., Cosmai, L., Gallieni, M., Pedrazzoli, P., and Malberti, F. (2015). Renal effects of targeted anticancer therapies. Nat. Rev. Nephrol. 11, 354-370. doi:10. 1038/nrneph.2015.15

Qiao, J. H., Fishbein, M. C., Demer, L. L., and Lusis, A. J. (1995). Genetic determination of cartilaginous metaplasia in mouse aorta. Arterioscler. Thromb. Vasc. Biol. 15, 2265-2272. doi:10.1161/01.atv.15.12.2265

Rahman, I., Kode, A., and Biswas, S. K. (2006). Assay for quantitative determination of glutathione and glutathione disulfide levels using enzymatic recycling method. Nat. Protoc. 1 (6), 3159-3165. doi:10.1038/nprot.2006.378

Reijers, J. A., and Burggraaf, J. (2015). Trastuzumab induces an immediate, transient volume increase in humans: a randomised placebo-controlled trial. EBioMedicine. 2, 953-959. doi:10.1016/j.ebiom.2015.05.002

Riccio, G., Antonucci, S., Coppola, C., D’Avino, C., et al. (2018). Ranolazine attenuates trastuzumab-induced heart dysfunction by modulating ROS production. Front. Physiol. 9, 38. doi:10.3389/fphys.2018.00038

Rygiel, K. (2016). Benefits of antihypertensive medications for anthracycline- and trastuzumab-induced cardiotoxicity in patients with breast cancer: insights from recent clinical trials. Indian J. Pharmacol. 48 (5), 490-497. doi:10. 4103/0253-7613.190719

Sadek, I., Keaton, M., Maihle, N. J., and Tang, S-C. (2017). Anti-HER-2 therapy following severe trastuzumab-induced cardiac toxicity. Gen. Dis. 4, 159-162. doi:10.1016/j.gendis.2017.07.007

Sharma, P., Hakimian, S., Camacho, J., and Chait, R. (2018). Prevention of chemoinduced cardiotoxicity with beta-blockers. J. Am. Coll. Cardiol. 71 (11 Suppl. 1), A1803. doi:10.1016/s0735-1097(18)32344-1

Shobha, J. R., Moor, V. J., Nouaga, M. E., Zing-Awona, B., Tchanana, G., and Ketcha, A. (2016). Atherogenic index of plasma and risk of cardiovascular disease among Cameroonian postmenopausal women. Lipids Health Dis. 15, 49. doi:10.1186/s12944-016-0222-7 
Siegel, R. L., Miller, K. D., and Jemal, A. (2020). Cancer statistics, 2017. CA Cancer J. Clin. 67, 7-30. doi:10.3322/caac.21387

Singh, D., Thakur, A., and Tang, W. H. (2015). Utilizing cardiac biomarkers to detect and prevent chemotherapy-induced cardiomyopathy. Curr. Heart Fail. Rep. 12 (3), 255-262. doi:10.1007/s11897-015-0258-4

Slaoui, M., and Fiette, L. (2011). Histopathology procedures: from tissue sampling to histopathological evaluation. Methods Mol. Biol. 691, 69-82. doi:10.1007/978-160761-849-2_4

Spector, N. L., and Blackwell, K. L. (2009). Understanding the mechanisms behind trastuzumab therapy for human epidermal growth factor receptor 2-positive breast cancer. J. Clin. Oncol. 27, 5838-5847. doi:10.1200/JCO.2009.22.1507

Teppo, H. R., Soini, Y., and Karihtala, P. (2017). Reactive oxygen species-mediated mechanisms of action of targeted cancer therapy. Oxid. Med. Cell. Longev. 2017, 1485283. doi: $10.1155 / 2017 / 1485283$

Thomas, S. A. (2017). Chemotherapy agents that cause cardiotoxicity. U.S. Pharm. 42 (9), HS24-33. doi:10.1177/001857870504001203

Tocchetti, C., Ragone, G., Coppola, C., Rea, D., Piscopo, G., Scala, S., et al. (2012). Detection, monitoring, and management of trastuzumab-induced left ventricular dysfunction: an actual challenge. Eur. J. Heart Fail. 14, 130-137. doi:10.1093/eurjhf/ hfr165

Vaduganathan, M., Hirji, S. A., Qamar, A., Bajaj, N., Gupta, A., Zaha, V., et al. (2019). Efficacy of neurohormonal therapies in preventing cardiotoxicity in patients with cancer undergoing chemotherapy. JACC CardioOncol. 1, 54-65. doi:10.1016/j.jaccao.2019.08.006

Varghese, F., Bukhari, A. B., Malhotra, R., and De, A. (2014). IHC Profiler: an open source plugin for the quantitative evaluation and automated scoring of immunohistochemistry images of human tissue samples. PLoS One 9 (5), e96801. doi:10.1371/journal.pone.0096801

Villecco, A. S., Cocci, C., and Di Emidio, M. (2004). Blood pressure control and weight loss in overweight or obese patients with previously treated or untreated mild to moderate hypertension given valsartan: an open-label study comparing pretreatment and posttreatment values. Curr. Ther. Res. Clin. Exp. 65 (2), 172-184. doi:10.1016/S0011-393X(04)90031-8

Vontas, J. G., Enayati, A. A., Small, G. J., and Hemingwa, J. (2000). A simple biochemical assay for glutathione $S$-transferase activity and its possible field application for screening glutathione $S$-transferase-based insecticide resistance. Pest. Biochem. Physiol. 68 (3), 184-192.

Wagner, S-A., Okwuosa, T. M., Barac, A., and Volgman, A. S. (2020). The role of Angiotensin-converting Enzyme inhibitors and $\beta$-blockers in primary prevention of cardiac dysfunction in breast cancer patients. JAHA. 9 (2), 5. doi:10.1161/JAHA.119. 015327
Winkels, R. M., Beijer, S., van Lieshout, R., van Barneveld, D., Hofstede, J., Kuiper J., et al. (2014). Changes in body weight during various types of chemotherapy in breast cancer patients. e-SPEN J. 9 (1), e39-44.

Wittayanukorn, S., Qian, J., Westrick, S. C., Billor, N., Johnson, B., and Hansen, R. A. (2018). Prevention of trastuzumab and anthracycline-induced cardiotoxicity using angiotensin-converting enzyme inhibitors or $\beta$-blockers in older adults with breast cancer. Am. J. Clin. Oncol. 41 (9), 909-918. doi:10.1097/COC. 0000000000000389

Witteles, R. M., and Bosch, X. (2015). Myocardial protection during cardiotoxic chemotherapy. Circulation 132, 1835-1845. doi:10.1161/CIRCULATIONAHA.114.010486

World Health Organization (2018). Cancer: key facts. WHO fact sheets. https:// www.who.int/news-room/fact-sheets/detail/cancer.

Yersal, Ö., Eryilmaz, U., Akdam, H., Meydan, N., and Barutca, S. (2018). Arterial stiffness in breast cancer patients treated with anthracycline and trastuzumabbased regimens. Cardiol. Res. Pract. 33, 64. doi:10.1155/2018/5352914

Yu, A. F., Yadav, N. U., Lung, B. Y., Eaton, A. A., Thaler, H. T., Hudis, C. A., et al. (2015). Trastuzumab interruption and treatment-induced cardiotoxicity in early HER2-positive breast cancer. Breast Cancer Res. Treat. 149, 489-495. doi:10.1007/s10549-014-3253-7

Yuan, M., Tse, G., Zhang, Z., Han, X., Wu, W. K. K., Li, G., et al. (2018). The incidence of atrial fibrillation with trastuzumab treatment: a systematic review and meta-analysis. Cardiovasc Ther. 36, e12475. doi:10.1111/1755-5922. 12475

Zablocki, D., and Sadoshima, J. (2013). Angiotensin II and oxidative stress in the failing heart. Antioxid. Redox Signal. 19 (10), 1095-1109. doi:10.1089/ars.2012. 4588

Zeglinski, M., Ludke, A., Jassal, D. S., and Singal, P. K. (2011). Trastuzumabinduced cardiac dysfunction: a 'dual-hit'. Exp. Clin. Cardiol. 16 (3), 70-74.

Conflict of Interest: The authors declare that the research was conducted in the absence of any commercial or financial relationships that could be construed as a potential conflict of interest.

Copyright (ㄷ 2021 Olorundare, Adeneye, Akinsola, Ajayi, Agede, Soyemi, Mgbehoma, Okoye, Albrecht, Ntambi and Crooks. This is an open-access article distributed under the terms of the Creative Commons Attribution License (CC BY). The use, distribution or reproduction in other forums is permitted, provided the original author(s) and the copyright owner(s) are credited and that the original publication in this journal is cited, in accordance with accepted academic practice. No use, distribution or reproduction is permitted which does not comply with these terms. 


\section{GLOSSARY}

ACE angiotensin-converting enzyme

ACEIs angiotensin-converting enzyme inhibitors

ADP amlodipine

AIP atherogenic index of plasma

ALB albumin

AMPK $5^{\prime}$ adenosine monophosphate-activated protein kinase

ANOVA Analysis of variance

ARBs angiotensin receptor blockers

AT1 angiotensin II receptor type 1

ATP adenosine triphosphate

Bax Bcl-2 associated x protein

BCL-2 B-cell lymphoma

Bcl-xL B-cell lymphoma-extra large

Bcl-xS B-cell lymphoma-extra small

BNP brain (B-type) natriuretic peptide

CAT catalase

CK-MB creatine kinase-MB

CRI coronary artery index

$\boldsymbol{c} \boldsymbol{T n I}$ cardiac troponin I

$\boldsymbol{c T n} \boldsymbol{T}$ cardiac troponin $\mathrm{T}$

DAB 3,3' diaminobenzidine

DPPH 1,1-diphenyl-2-picrylhydrazyl

DPX Dibutylphthalate polystyrene

DTNB 5,5-dithiobisnitro benzoic acid

ELISA Enzyme-linked immunosorbent assay

ErbB2 human erythroblastic leukemic viral oncogene B2

ET-1 endothelin-1

GPx glutathione peroxidase

GSH reduced glutathione

GST glutathione S-transferase

$\mathbf{H}_{2} \mathrm{O}_{2}$ hydrogen peroxide

HCl hydrochloric acid

HDL-c high density lipoprotein cholesterol fraction

HER-2 human epidermal growth factor receptor-2
IHC immunohistochemistry

i.p. intraperitoneal

$\mathbf{K C l}$ potassium chloride

LASUCOM Lagos State University College of Medicine

LDH lactate dehydrogenase

LDL-c low density lipoprotein cholesterol fraction

LSP lisinopril

MDA malondialdehyde

MAPK mitogen activated protein kinase

MPTP mitochondrial permeability transition pore

NADPH nicotinamide adenine dinucleotide phosphate

NO/cGMP nitric oxide-cyclic guanosine monophosphate

NRG-1/ErbB neuregulin-1/erythroblastic leukemia viral oncogene

PI3k/Akt phosphatidylinositol 3-kinase/protein kinase B

p.o. per os

$\% \Delta$ bwt. percentage change in weight

RAS renin angiotensin system

RKW relative kidney weight

RLW relative liver weight

ROS reactive oxygen species

S.D. standard deviation

S.E.M. standard error of the mean

SOD superoxidase dismutase

TBA thiobarbituric acid

TC total cholesterol

TCA tricarboxylic acid

TG triglyceride

TP total protein

TZM trastuzumab (r-DNA origin)

UERC University Ethics and Research Committee

UNILORIN University of Ilorin

UV ultraviolet

VAL valsartan

VLDL-c very low density lipoprotein cholesterol fraction

XO xylenol orange 